\title{
An Experimental Investigation on Flexural Behavior of Reinforced Concrete Beams Strengthened by an Intelligent CFRP Plate with Built-In Optical Fiber Bragg Grating Sensors
}

\author{
Zhi Zhou $\mathbb{D}^{1,2}$ and Zhenzhen Wang $\mathbb{D}^{1}$ \\ ${ }^{1}$ Institute of Smart Structures, Dalian University of Technology, Linggong Road No. 2, Ganjingzi District, Dalian 116024, China \\ ${ }^{2}$ State Key Laboratory of Coastal and Offshore Engineering, Dalian University of Technology, Linggong Road No. 2, Ganjingzi \\ District, Dalian 116024, China \\ Correspondence should be addressed to Zhi Zhou; zhouzhi@dlut.edu.cn
}

Received 17 September 2017; Revised 10 December 2017; Accepted 31 December 2017; Published 16 July 2018

Academic Editor: Carlos Ruiz

Copyright (c) 2018 Zhi Zhou and Zhenzhen Wang. This is an open access article distributed under the Creative Commons Attribution License, which permits unrestricted use, distribution, and reproduction in any medium, provided the original work is properly cited.

\begin{abstract}
The difficulties induced from high-durability package, large-scale measurement, and sensor installation make it a big challenge but an urgent need to predict the mechanical behavior of strengthened reinforced concrete structure with the externally bonded fiber-reinforced polymer (FRP) plate under harsh environments and rough construction process. In an effort to solve this challenge, this paper proposes a novel end anchored self-sensing CFRP plate assembly with built-in optical fiber Bragg grating (FBG) sensor. The self-sensing principle is presented and a demonstration test was carried out in the laboratory in order to investigate the self-sensing properties of the intelligent CFRP plate. Three-point flexural tests of a total of ten RC beams were carried on: six strengthened with the bonded or unbonded posttensioned intelligent CFRP plates, one strengthened with the ordinary CFRP plate, and three strengthened with the control beams. The full-range CFRP plate strain at the maximum moment was measured utilizing the FBG interrogator. Using this monitoring data, the short-term prestress loss attributed to anchorage set and the relationship between the external load and the CFRP strain at the middle span associated with the integral response of the strengthened member were investigated. Besides, the objective of the tests was also to gain a better understanding of the failure mode and the flexural behavior of RC beams strengthened with posttensioned CFRP plates taking into account the different strengthening methods, initial damage, and the dead load before strengthening. The experimental results showed that the developed CFRP plate with built-in FBG sensors not only can be the reinforcement of the RC structures, but also provide an effective way to monitor the full-range behavior of the CFRP plate with the excellent self-sensing property shown in the demonstration tests.
\end{abstract}

\section{Introduction}

From the mid-1980s and continuing to the present time, a vast number of concrete, metallic, and masonry structures were/ are in urgent need of repair/strengthening/rehabilitation, due to either a change in use or structural degradation. Furthermore, many concrete, metallic, timber, and masonry structures were built prior to the introduction of modern design codes and hence do not meet modern design requirements [1]. The extraordinary properties of FRP composites, including lightweight, high-strength-to-weight ratio, high-energy absorption, corrosion and fatigue resistance, potentially high overall durability and tailorability, high specific attributes, and ease of transportation and handling, enable them to be used in areas where the conventional construction materials might be restricted $[1,2]$. Some initially exploratory work has been done on the use of FRP to strengthen concrete structures in the early 1980s [3-6]. Professor Urs Meier and his team at the Swiss Federal Laboratories for Materials Testing and Research (EMPA) began research in the mid1980s on the use of carbon fiber-reinforced polymer (CFRP) composites as external reinforcement for strengthening 
structures. This was the first worldwide systematical research work in the field of FRP composites for strengthening in civil engineering [2]. The idea of posttensioned CFRP strips with mechanical anchors for the strengthening of RC beams under bending began also at EMPA in the early 1990s as part of a Ph.D. thesis [7]. In the following three decades, the use of externally bonded posttensioned FRP plates to reinforced concrete (RC) structures for structural flexural reinforcement is widely deployed as a practice, and extensive experimental and theoretical researches have been conducted on the failure modes and mechanical properties of the posttensioned CFRP plate-strengthened RC flexural members and structures [8-24]. Posttensioned FRP reinforcement enables the stress in the internal reinforcing steel and deflections will decrease, the crack widths reduced, both the serviceability and the durability of a structure in addition, the material to become more efficient since a greater portion of its tensile capacity is employed. Investigations have shown that prestressed FRPs are effective materials for strengthening deteriorated structures due to its low weight, high tensile strength, corrosion resistance, good resistance to degradation and creep, electromagnetic neutrality, quick and easy construction, low relaxation losses, and low labor costs and have an ability to modify the elastic modulus [25-27]. Prestressed FRPs have limited tensile strain capacity, and the sudden failures of the FRPs may occur without premonitory when the stress exceeds its ultimate tensile strength due to its natural elastic-brittle property. Moreover, the behavior of the CFRP plates in field application is generally influenced by various factors, for example, dimension, bonding length, interfacial nature, surface condition of concrete beam, and installation technique, which make the theoretical methods unable to capture the behavior of the CFRP plates accurately. Therefore, the strain monitoring of the posttensioned FRP strengthening system under different prestressing techniques in the whole loading history is prime pursued to understand the behavior of the CFRP plates in field application and validate the suitability of prestressed CFRP in the strengthening of RC beams and further predict the real-time bending resistance of the RC member based on the monitoring data at the control section for the safety assessment of the strengthened structures.

Nowadays, the most commonly used method to monitor and assess the mechanical behavior of the CFRP plate on RC structures is electrical resistance strain gauges, which can effectively provide the information about the performance of the CFRP plate during the static and short-term prestressing loss stage [13]. Unfortunately, the measurement accuracy and long-term stability of this technique is vulnerable to the environmental disturbances, for example, corrosion and electromagnetic interference and inconvenience for long-distance data transmission, which limits its long-term applications in the field application [28]. So, it is imperative to develop a technique with high durability and long-term stability for the CFRP plate in strengthening RC structures for in situ applications under the harsh environment. More recently, the use of a structural health monitoring systems (SHMS) for evaluating the durability, serviceability, and safety of the structures reinforced through composite materials in real time shows great potential by incorporating fiber optical sensors (FOSs) in composite materials during its forming process (e.g., wet lay-up process or pultrusion process); they offer a variety of advantages, for example, durability in harsh environment, immunity to electromagnetic interference, small size, and higher material compatibility. The FBG sensing technology with great potential for applications in the FOSs embedded into the composite materials is used for strain and temperature sensing at the local control section of strengthened members owing to its high sensitivity, repeatability, accuracy, and quasi-distributed and single-ended measurement [29-40]. Lu and Xie exploited the smart hand wet laid-up CFRP sheets embedded with the FBG sensor to strengthen the RC beams, and the load effect of the strengthening $\mathrm{RC}$ beam has been assessed by the smart CFRP sheet measurements [30, 31]. Wang and Zhou proposed a smart composite laminates embedded with FBG sensor into the interlayer of the FRP during the wet lay-up process, and their sensing precisions of strain and temperature have been predicted experimentally [33]. Sundaram et al. utilized fiber Bragg grating (FBG) sensor to monitor the interfacial strains in FRP-repaired concrete elements. The study reported here aims at monitoring the initiation and propagation of debonding failure and also at developing a suitable methodology of measurement for field monitoring of repaired members [37]. Valvona and Toti proposed an innovative seismic retrofitting technique for masonries made by glass-fiber-reinforced cement matrix (GFRCM) grids and textiles with a modern integrated fiber optic sensing system [39]. Zhang and Yu present an experimental study on the FRP strengthening of RC cantilever slabs with insufficient anchorage of steel reinforcing bars and the associated strain monitoring using FBG sensors. The experimental program was designed to support a real FRP strengthening project [40]. The above researches have generally verified the excellent performance of FBG sensors in the strain monitoring of FRP composites.

Against this background, this paper presents a novel durable intelligent CFRP plate strain monitoring assembly with end anchorages using FBG sensors, and the associated experimental study on the posttensioned CFRP strengthening of RC beams was carried out. The experimental arrangement included a demonstration test for its self-sensing properties as well as the posttensioned CFRP strengthening of RC beams under different conditions (e.g., strengthening methods, loading history, and initial damage) to achieve a clear understanding of the behavior of the strengthening system and the strain monitoring system.

\section{Fabrication of the Intelligent CFRP Plate and Its Self-Sensing Properties}

2.1. Fabrication of the Intelligent CFRP Plate and Its SelfSensing Principles. Figure 1 gives the schematic of the configuration and its fabrication process of the proposed intelligent CFRP plate which consists of a CFRP plate and a built-in FBG sensor. The CFRP fibers are driven out in a dip-type epoxy bath by the pulling force supplied by two sets of counter rotating wheels under a consistent speed, and then the FBG sensor would go through a predesigned hole in the 


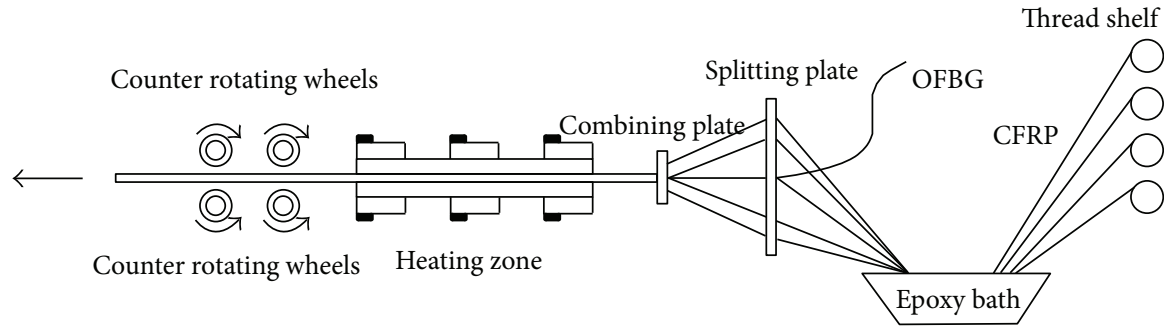

FIGURE 1: The schematic diagram of the manufacture process of the smart FBG-CFRP.

middle of the splitting plate and emerge into the CFRP fibers through combiner plates then evenly distribute to go through the cross section of a plate. The fabrication process was then followed by heating the polymer-reinforced fibers through the furnace possessing three temperature zones equipped with separate temperature controller. With the high temperature effect (about $200^{\circ} \mathrm{C}$ ) from the heating furnace, the FBG sensor and CFRP fibers were condensed into the intelligent CFRP plate by the cured epoxy. After fabricating the CFRP plate, the built-in FBG sensor would be extended at one end to develop the front/back jumpers by fusing additional jacket fibers. Finally, the CFRP plate was anchored by the wedge anchorage at two ends. The wedge-type anchorage relies on both friction and epoxy [41, 42], as shown in Figure 2. This anchorage used epoxy in the CFRP-wedge interface and steel-steel friction in the barrel-wedge interface. This wedge-type anchorage was made of a square steel anchoring barrel with a wedge hole in the center and two wedge clips. The steel and epoxy had various depths. On the wedge-CFRP plate surface, epoxy was applied and a ribbed surface was produced in the epoxy surface by grooves. The CFRP plate clamped by wedge clips was pushed into the wedge hole in the center of the anchoring steel barrel by using the specific anchorage pressing device. The wedge clips were moved along with the CFRP plate when tensioning pressing and the wedge clips were fixed at the anchoring hole eventually. Therefore, the CFRP plate was clamped tightly by the pressing force. While designing this anchor, the focus was to control the contact pressure and the tensile stress, primarily at located at the CFRP-wedge interface.

The mechanical and environmental associated information (e.g., strain and temperature) of the CFRP plate would be measured by the FBG sensor utilizing the FBG interrogating technique. Figure 3 shows the prototype of the proposed self-sensing CFRP plate.

An FBG only reflects specified wavelengths related to its grating period for an input light from a broadband source. The center of the reflected wavelengths is known as Bragg wavelength. The Bragg wavelength $\left(\lambda_{\mathrm{B}}\right)$ can be calculated as follows:

$$
\lambda_{\mathrm{B}}=2 n_{\text {eff }} \Lambda,
$$

where $n_{\text {eff }}$ is the effective refractive index, and $\Lambda$ is the grating period of the fiber. Under the pulling loads, the axial strains along the FRP anchor can be recorded by these embedded FBG sensors. Assuming that the cross-coupling effect of strain and temperature is negligible, the Bragg wavelength shifts of the FBG sensors are linearly proportional to the applied strain and environment temperature change [43-45]:

$$
\Delta \lambda_{\mathrm{B}}(\Delta \varepsilon, \Delta T)=\alpha_{\varepsilon} \Delta \varepsilon+\alpha_{T} \Delta T .
$$

For the FBG sensor under constant strain, the related Bragg wavelength shift is caused by the temperature vibration yields:

$$
\Delta \lambda_{\mathrm{B}}(0, \Delta T)=\alpha_{T} \Delta T .
$$

The applied strain considering temperature compensation can be then determined as:

$$
\Delta \varepsilon=\frac{\left(\Delta \lambda_{\mathrm{B}}(\Delta \varepsilon, \Delta T)-\Delta \lambda_{\mathrm{B}}(0, \Delta T)\right)}{\alpha_{\varepsilon}},
$$

where $\Delta \lambda_{\mathrm{B}}$ is the Bragg wavelength shift; $\Delta \varepsilon$ and $\Delta T$ are the applied strain and environment temperature change; $\alpha_{\varepsilon}$ and $\alpha_{T}$ are the strain and temperature sensitivity coefficients of the FBG sensor, respectively. Additionally, the quantity of the embedded FBG sensors and their locations can be designed according to the measurement requirements in field application.

2.2. Calibration Test. To calibrate the FBG sensors in the CFRP plate, four intelligent CFRP plates were manufactured following the procedure described in the last section and tested in the laboratory. The specimen has a dimension of $2000 \mathrm{~mm} \times 50 \mathrm{~mm} \times 2 \mathrm{~mm}$. It is assumed that the FBG will not affect the mechanical properties of the CFRP plate due to its small size of $125 \mu \mathrm{m}$ in diameter. Figure 4 shows the experimental setup for the calibration test. The specimen was fixed on a reaction frame and a hydraulic jack was used to provide the static loading. Three levels of static load were applied including $100 \mathrm{kN}, 120 \mathrm{kN}$, and $150 \mathrm{kN}$ with a loading step of $10 \mathrm{kN}$ and a static holding time of $2 \mathrm{~min}$. The calibration was performed for three times to get the repeatability of the sensor. The strains of CFRP plate were recorded by the strain gauges, as well as the FBG sensors embedded. Table 1 shows the detail of specimen dimensions and mechanical properties of each CFRP specimen. The CFRP used in this study has an average Young's modulus of $153.7 \mathrm{GPa}$ and an average maximum elongation of $1.61 \%$. Table 2 gives the detail of the intelligent CFRP plates. Figure 5 shows the calibrated strain-wavelength curves and all the sensing characteristics of each specimen are summarized in Table 3. The average strain sensitivity of the FBG-CFRP plate is $1.228 \mathrm{~nm} / \mu \varepsilon$ with a maximum detection dynamic range of 


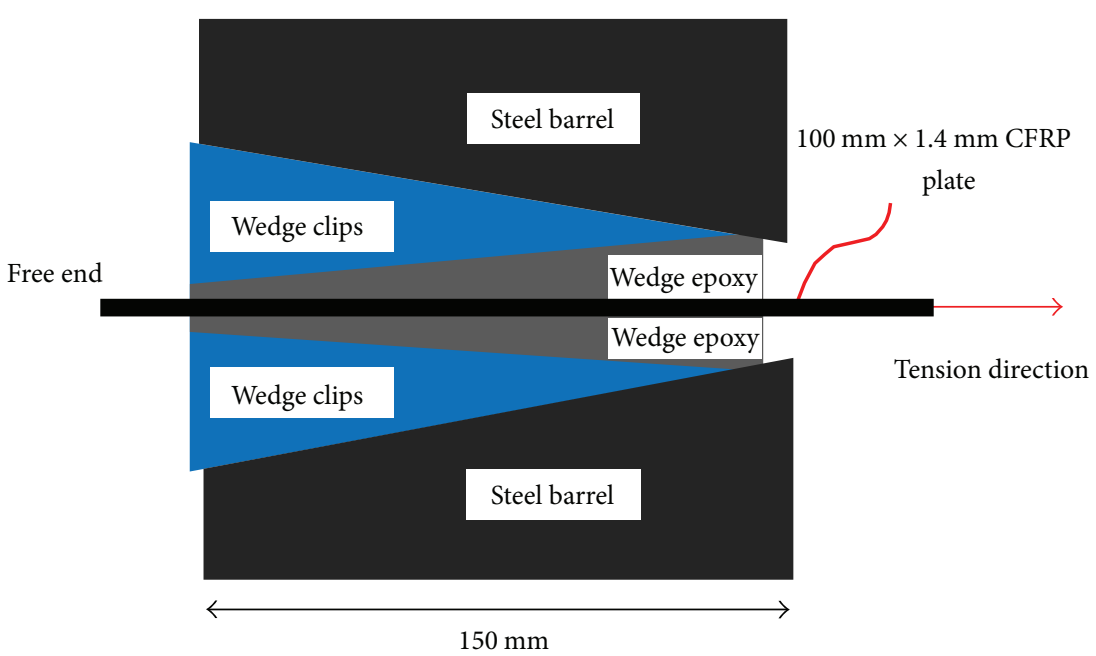

Figure 2: Schematic diagram of the wedge-type anchorage.

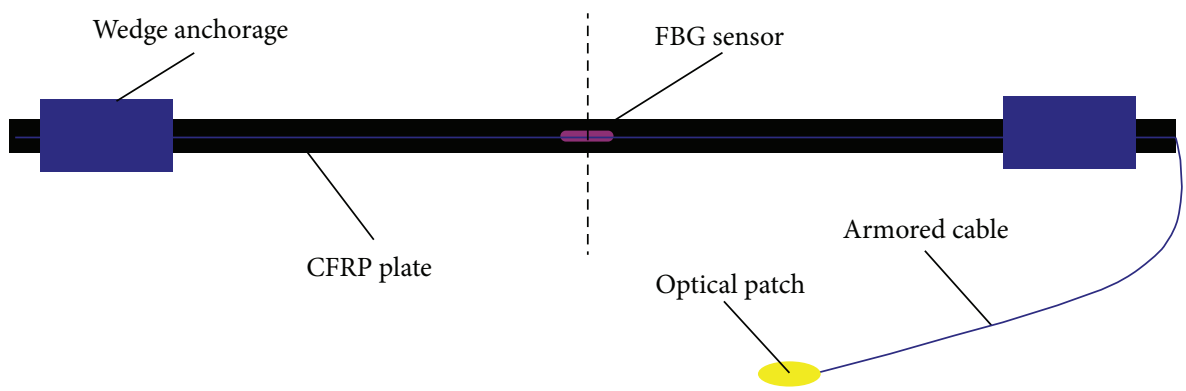

(a)

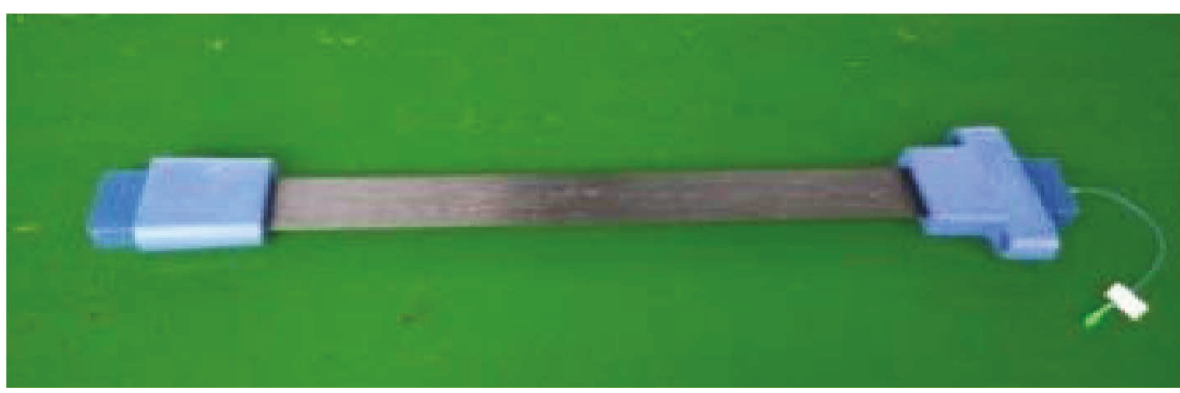

(b)

FIgURE 3: The schematic diagram of the smart CFRP.

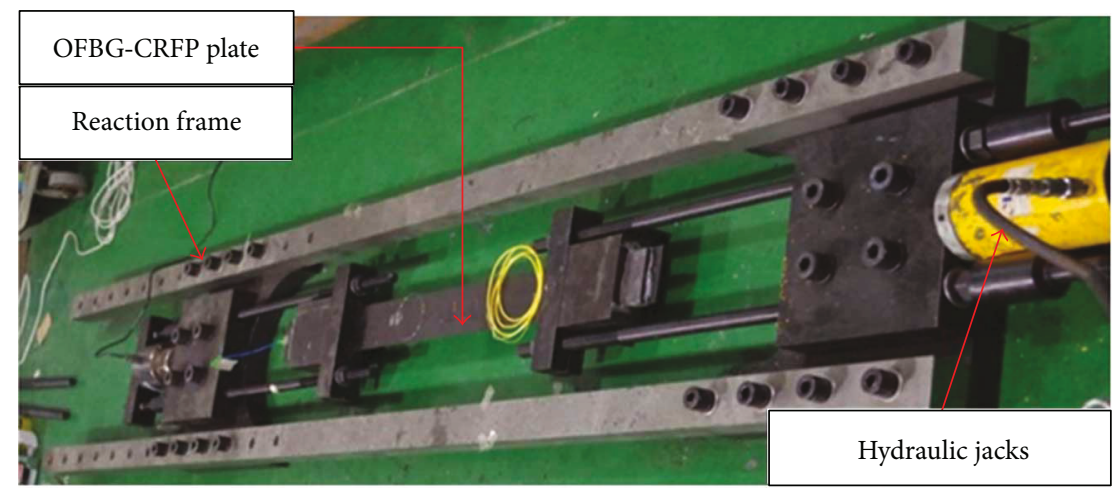

Figure 4: Tension reaction frame. 
TABLE 1: Mechanical properties for the CFRP plates.

\begin{tabular}{|c|c|c|c|c|c|c|}
\hline Specimen & Thickness (mm) & Width (mm) & Failure load $(\mathrm{kN})$ & Tensile strength $(\mathrm{MPa})$ & Elongation (\%) & Tensile modulus (GPa) \\
\hline 1 & 2.07 & 10.22 & 50.084 & 2461.99 & 1.66 & 142.5 \\
\hline 2 & 2.08 & 10.37 & 56.527 & 2620.67 & 1.70 & 156.9 \\
\hline 3 & 2.05 & 10.38 & 50.852 & 2389.79 & 1.66 & 148.9 \\
\hline 4 & 2.08 & 10.19 & 55.645 & 2625.37 & 1.61 & 159.6 \\
\hline Average & 2.07 & 10.29 & 53.694 & 2521.59 & 1.61 & 153.7 \\
\hline
\end{tabular}

Table 2: Detail of the intelligent CFRP plates.

\begin{tabular}{lccc}
\hline Specimen & $\begin{array}{c}\text { Initial Bragg } \\
\text { wavelength }(\mathrm{pm})\end{array}$ & $\begin{array}{c}\text { Width*height } \\
\left(\mathrm{mm}^{*} \mathrm{~mm}\right)\end{array}$ & $\begin{array}{c}\text { Calibration } \\
\text { load }(\mathrm{kN})\end{array}$ \\
\hline SC-1 & 1524.727 & $50^{*} 3$ & 100 \\
SC-2 & 1547.565 & $100^{*} 1.4$ & 150 \\
SC-3 & 1546.617 & $50^{*} 3$ & 120 \\
SC-4 & 1522.016 & $100^{*} 1.4$ & 100 \\
\hline
\end{tabular}

above 7,000 $\mu \varepsilon$. Table 2 clearly shows that the FBG-CFRP plate, as a sensor, has linearity, repeatability, and hysteresis higher than $99 \%$ and accuracy higher than $98 \%$.

\section{Posttensioned Self-Sensing FBG-CFRP Plates for Structural Strengthening}

To apply the developed FBG-CFRP plates for structural strengthening of concrete structures, a posttensioned tension device and anchorage system were adopted as shown in Figure 6 . To avoid eccentricity along the interface between the CFRP plate and the concrete substrate, drilling holes and grooves were made to embed anchoring bolts for the steel plates, which were fastened directly into the RC beam. Prior to the application of the posttension force, structural adhesive was injected beneath the CFRP plate and the tension force was applied to the CFRP plate before the adhesive curing (24 hours of curing time). The tension process was applied in five loading steps: $20 \% \sigma \mathrm{con}, 40 \% \sigma \mathrm{con}, 60 \% \sigma \mathrm{con}$, $80 \% \sigma \mathrm{con}$, and $100 \% \sigma \mathrm{con}$. The wedge-type anchorage was driven to remove the posttension devices and remain the tension force on the FBG-CFRP plate. Figure 7 shows the photos of actual strengthening system.

\section{Experimental Setup}

4.1. Experimental Specimens and Program. The experimental program included the testing of seven posttensioned CFRPstrengthened reinforced concrete beams to understand the structural behavior of such strengthened reinforced concrete beams and to demonstrate the effectiveness of the developed intelligent CFRP laminate strain monitoring system. Details of the experimental program are presented in this section. The RC slabs were $4000 \mathrm{~mm}$ long, with a cross section of $300 \mathrm{~mm}$ (width) by $350 \mathrm{~mm}$ (height). Nine RC beams were reinforced with $2 \phi 22$ rebars and $3 \phi 18$ rebars in the tension zone and five $\phi 10$ rebars in the compression zone, respectively. The transverse reinforcement was composed of closed steel stirrups of $\phi 10$ with $100 \mathrm{~mm}$ of longitudinal spacing, as shown in Figure 8. Strengthening was performed by using $1900 \mathrm{~mm}$-long CFRP laminate strips with a rectangular cross section of $1.4 \mathrm{~mm}$ by $100 \mathrm{~mm}$.

The experimental program included 10 reinforced concrete beams as presented in Table 4: (i) three control specimens without strengthening including one without initial damage (RC-0), one with an artificially constructed crack at the middle span (RC-AC), and one with low reinforcement ratio (RC-LR); (ii) three beams were strengthened with externally bonded posttensioned intelligent CFRP plates at the bottom of the grooved RC beam with no dead loads applied before strengthening (B-GR-0-T, B-AC-0-T, and B-LR-0-T), as shown in Figure 9(b); (iii) two beams were strengthened with unbonded posttensioned intelligent CFRP plates at the bottom of the grooved RC beam with 0 and $300 \mathrm{kN}$ dead load before strengthening (UB-GR-0-T, UB-GR-300-T), as shown in Figure 9(b); and (iv) two beams were strengthened with external unbonded posttensioned smart FBG-CFRP plates at the direct bottom of the ungrooved RC beam with 0 and $300 \mathrm{kN}$ dead load before strengthening, respectively (UBNG-0-T and UB-NG-300-T), as shown in Figure 9(a).

4.2. Test Material Characterization. Material characterization included the evaluation of the mechanical properties of the materials involved in this experimental program, namely, concrete, steel, CFRP plate, and epoxy adhesive. Readymixed concrete was used to prepare the test beams, which had been aged for 28 days. A single batch was mixed to cast all beams and testing samples. For characterizing the mechanical properties of the concrete, six cube specimens with $150 \mathrm{~mm}$ (height) by $150 \mathrm{~mm}$ (width) by $150 \mathrm{~mm}$ (length) were used for each series. The compressive strength and elastic modulus of the test beams were tested to be 47.67 MPa and 35.071GPa. The pultruded CFRP plates were used in this study, which possess a smooth external surface and consist of unidirectional carbon fibers (fiber volume content is higher than 68\%) held together by an epoxy vinyl ester resin matrix. The cross-sectional dimension of the unidirectional CFRP plates is $100 \mathrm{~mm} \times 1.4 \mathrm{~mm}$. The detail of material properties of the steel reinforcements, CFRP, and epoxy resin adhesive used in the laboratory experiments can be seen in Table 5.

4.3. Test Configuration and Instrumentation. In order to assess the behavior of all specimens in service and ultimate design conditions, monotonic tests up to failure were performed using a three-point bending scheme with the force imposed centrally at the midspan section as seen in Figure 10. The instrumentation included (i) three linear 


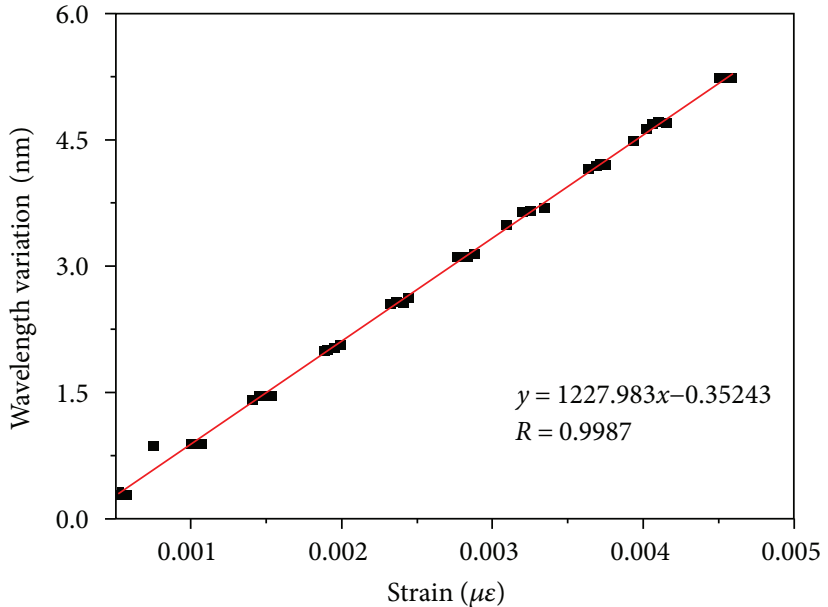

- Test value

_ Linear fit value

Calibration curve of specimen SC-1

(a) Calibration curve of specimen SC-1

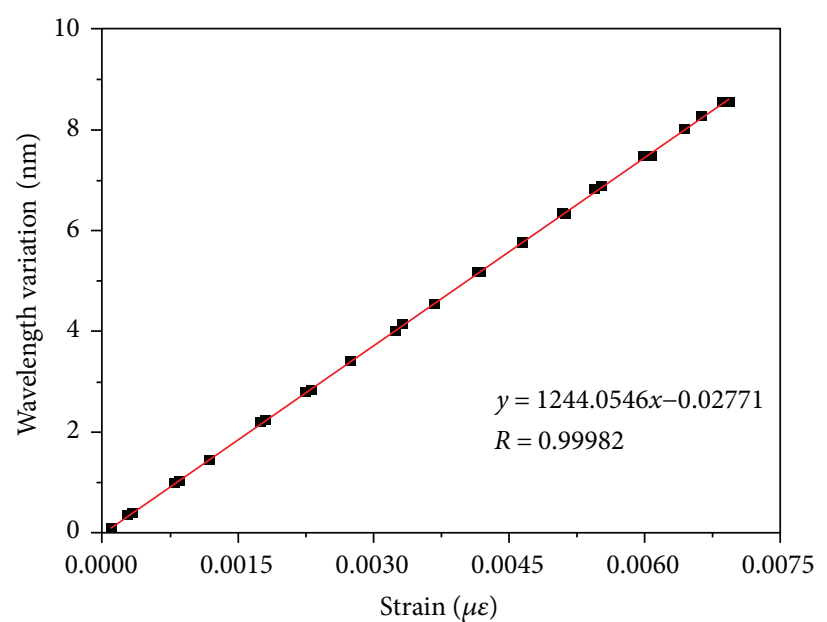

- Test value

Linear fit value

Calibration curve of specimen SC-3

(c) Calibration curve of specimen SC-3

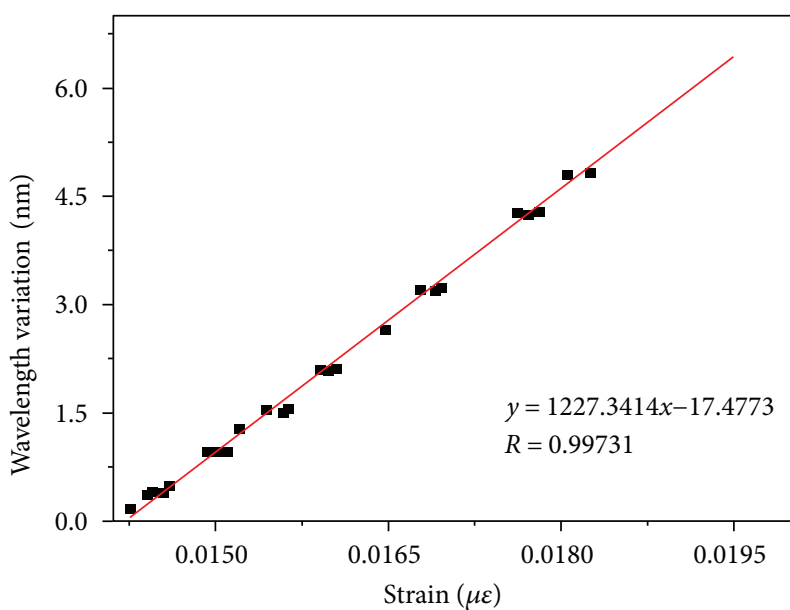

- Test value

Linear fit value

Calibration curve of specimen SC-2

(b) Calibration curve of specimen SC-2

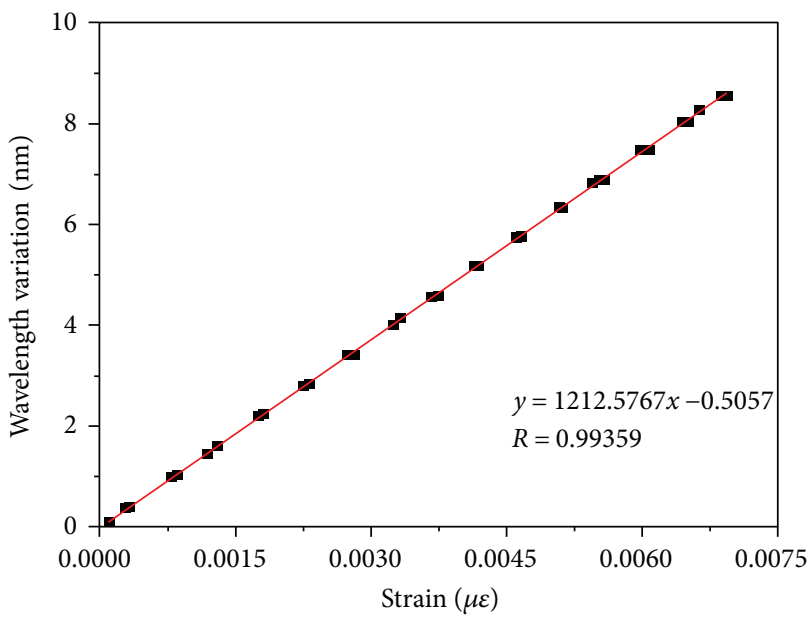

- Test value

Linear fit value

Calibration curve of specimen SC-4

(d) Calibration curve of specimen SC-4

FIGURE 5: Strain sensing sensitivity of FBG-CFRP plates.

TABLE 3: Static sensing characteristics for the FBG-CFRP plates.

\begin{tabular}{lccccccc}
\hline Specimen & Sensitivity $(\mathrm{pm} / \mu \varepsilon)$ & Linearity & Repeatability & Hysteresis & Measuring range $(\mu \varepsilon)$ & Resolution & Overall accuracy \\
\hline SC-1 & 1.228 & $0.318 \%$ & $0.662 \%$ & $0.197 \%$ & 7041 & $0.01160 \%$ & $0.726 \%$ \\
SC-2 & 1.227 & $1.290 \%$ & $0.716 \%$ & $0.380 \%$ & 8402 & $0.00970 \%$ & $1.7 \%$ \\
SC-3 & 1.244 & $0.708 \%$ & $0.894 \%$ & $0.192 \%$ & 8603 & $0.00937 \%$ & $1.16 \%$ \\
SC-4 & 1.212 & $0.897 \%$ & $0.242 \%$ & $0.208 \%$ & 8806 & $0.00992 \%$ & $1.183 \%$ \\
Average & 1.228 & $0.803 \%$ & $0.629 \%$ & $0.244 \%$ & 8213 & $0.0101 \%$ & $1.1923 \%$ \\
\hline
\end{tabular}

variable differential transducers (LVDTs) to record the deflection were installed at the supports and the applied load points along the longitudinal axis of the beam; (ii) six electrical resistance strain gauges were installed at midspan of the beam from the top surface of the concrete to the bottom along the height direction with the constant intervals of $100 \mathrm{~mm}, 2$ strain gauges were mounted on the two bottom steel reinforcement at the middle span, and 5 were attached 


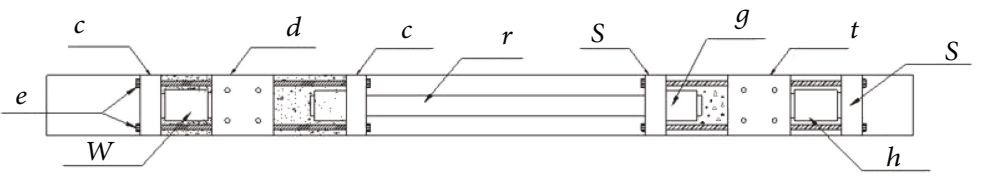

(a) Plan view

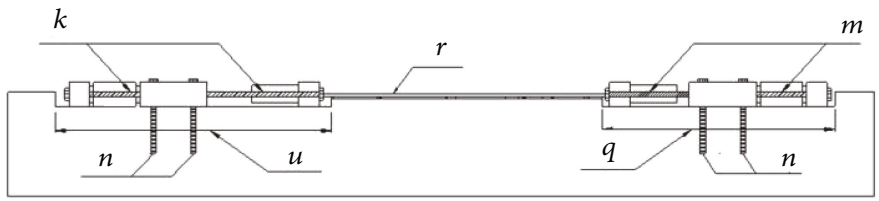

(b) Front view

FIgURE 6: Posttensioned CFRP plates tension device and anchorage system. $c, s$-reaction force steel plates at the tension end and fixed end, respectively; $d, t$-the anchoring steel plates at the tension end and fixed end; $e$-mechanical bolts; $g$-wedge-type anchorage; $h$-load cell sensor; $k, m$-tension rods at the tension rod and fixed end; $n$-anchoring bolts; $q, u$-groove at the tension end and the fixed end; $r$-CFRP plate and epoxy adhesive; $w$-the hydraulic jacking.

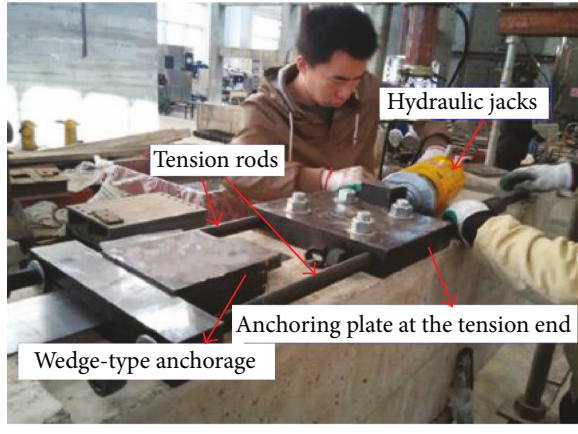

(a) The tension end

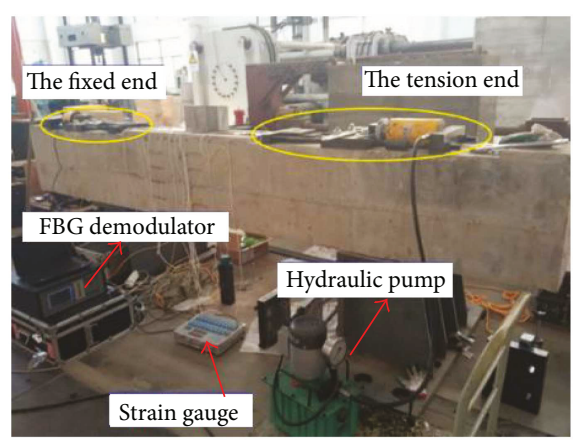

(b) Overall view

Figure 7: In situ photo of the strengthening system.

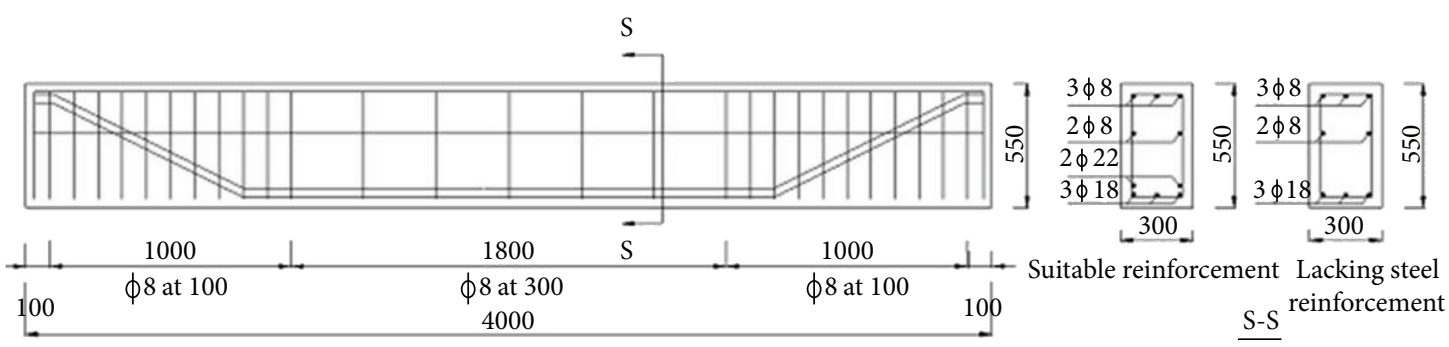

Figure 8: Details of the test specimens.

on the CFRP plates with constant spacing of $200 \mathrm{~mm}$; (iii) one FBG sensor embedded in the CFRP plate located just below the middle section; and (iv) one load cell to measure the applied load P.

There are two stages in this experimental work: (1) the short-term prestressing loss stage occurring in the first 24 hours. The measurement of the short-term prestressing loss was performed using the strain gauges installed on the CFRP plate together with the embedded FBG in CFRP plates at each tension step and at 5 minutes, 10 minutes, 30 minutes, 1 hour, and every 1 hour after anchoring and (2) the threepoint bending monotonic test stage following the shortterm prestressing loss stage. The load was applied gradually on the beam with an MTS controller-testing machine at the rate of $0.1 \mathrm{kN} / \mathrm{s}$ to the first crack appeared and then at the rate of $0.2 \mathrm{kN} / \mathrm{s}$ till the yielding of the longitudinal reinforcement. After that, the load was applied using displacement control at a constant displacement rate of $3 \mathrm{~mm} / \mathrm{min}$ until failure. The data from the FBG sensor were recorded using the TFBFGD-9000 FBG demodulator. All the signals from LVDTs, strain gauges, and load cells were recorded by IMC data acquisition system.

\section{Results and Discussion}

5.1. Short-Term Prestress Loss Measured by the Intelligent CFRP Plate. Short-term prestress loss of this strengthening system adopted in this paper is mainly induced by the 
TABLE 4: Strengthening details of test beams.

\begin{tabular}{|c|c|c|c|c|c|}
\hline Test specimen & Dead load before strengthening $(\mathrm{kN})$ & Initial damage & Bonding & Grooving & CFRP type \\
\hline $\mathrm{RC}-0$ & 0 & None & - & - & - \\
\hline $\mathrm{RC}-\mathrm{AC}$ & 0 & Artificially cracked & - & - & - \\
\hline RC-LR & 0 & Low reinforcement ratio & - & - & - \\
\hline B-GR-0-T & 0 & None & Bonded & Grooved & Smart \\
\hline B-CR-0-T & 0 & Artificially cracked & Bonded & Grooved & Smart \\
\hline B-MS-0-T & 0 & Low reinforcement ratio & Bonded & Grooved & Smart \\
\hline UB-GR-0-T & 0 & None & Unbonded & Grooved & Smart \\
\hline UB-GR-300-T & 300 & Previously cracked & Unbonded & Grooved & Smart \\
\hline UB-NG-300-T & 300 & Previously cracked & Unbonded & Nongrooved & Smart \\
\hline UB-NG-0-T & 0 & None & Unbonded & Nongrooved & Normal \\
\hline
\end{tabular}

Note: B: bonded; GR: grooved; T: three-point bending tests; AC: precracked; LR: low reinforcement ratio bars; UB: unbonded; smart: CFRP plates with built-in FBG sensor.

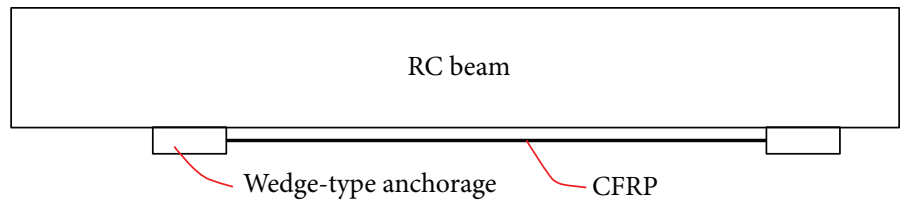

(a) Ungrooved

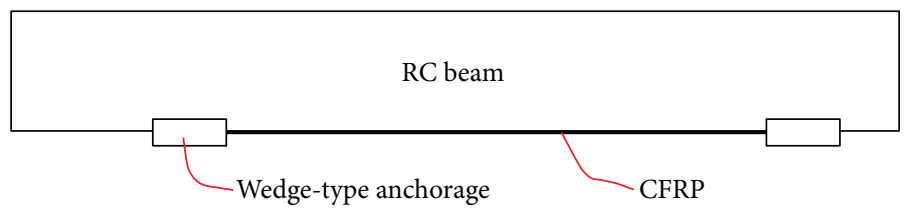

(b) Grooved

FIgURE 9: Schematic diagram of the strengthen system.

TABLE 5: Mechanical properties for the test materials.

\begin{tabular}{|c|c|c|c|c|c|}
\hline Test materials & Specification & Yield strength $\left(\mathrm{N} / \mathrm{mm}^{2}\right)$ & Tensile strength $\left(\mathrm{N} / \mathrm{mm}^{2}\right)$ & Elastic modulus $\left(\mathrm{N} / \mathrm{mm}^{2}\right)$ & Elongation (\%) \\
\hline Epoxy resin adhesive & $A+B$ & - & 51.3 & 3558.3 & 1.6 \\
\hline CFRP plate & $100 \mathrm{~mm} \times 1.4 \mathrm{~mm}$ & - & 2521.59 & $153.7 \times 103$ & 1.6 \\
\hline Steel bars HPB300 & $8 \mathrm{~mm}$ & 304 & 479 & $210 \times 103$ & 32 \\
\hline Steel bars HPB335 & $18 \mathrm{~mm}$ & 380 & 575 & $200 \times 103$ & 34 \\
\hline Steel bars HPB335 & $22 \mathrm{~mm}$ & 410 & 565 & $200 \times 103$ & 24 \\
\hline
\end{tabular}

retraction of the posttensioned CFRP plate due to the relative slippage between the CFRP plate and anchoring clips after the prestress force transferring to the anchoring system. The short-term prestress loss was calculated by the equation based on the measured center wavelength of the FBG sensor embedded into the intelligent CFRP plate, and then the anchorage set of the posttensioned CFRP plate was inversed by (2) according to the calculated prestressing loss.

$$
\begin{aligned}
& \Delta \sigma_{l 1}=E_{\mathrm{cf}} \Delta \varepsilon=\frac{\left[E_{\mathrm{cf}}\left(\Delta \lambda_{\mathrm{B}}(\Delta \varepsilon, \Delta T)-\Delta \lambda_{\mathrm{B}}(0, \Delta T)\right)\right]}{1.228}, \\
& \Delta \sigma_{l 1}=E_{\mathrm{cf}} \frac{\Delta_{\mathrm{a}}}{l},
\end{aligned}
$$

where $\Delta \sigma_{l 1}$ is the prestress loss associated with anchorage set $(\mathrm{MPa}), \Delta_{\mathrm{a}}$ is the slip of the anchorage integrated from measured strains $(\mathrm{mm}), E_{\mathrm{cf}}$ is the elastic modulus of the CFRP plate $(\mathrm{MPa})$, and $l$ is the CFRP length $(\mathrm{mm})$. As listed in Table 6 , the anchorage set ranges from $0.57 \mathrm{~mm}$ to $0.76 \mathrm{~mm}$ for all the test beams with an average value is $0.67 \mathrm{~mm}$ and the prestress loss maintains in the range from $81.83 \mathrm{MPa}$ to $108.90 \mathrm{MPa}$ with the corresponding prestress loss rate ranging from $11.5 \%$ to $15.2 \%$. On the basis of the calculation results, the anchorage set of the wedge-type anchorage is relatively smaller comparing to the flat anchorage and waveform anchorage. Up to date, there are no recommendations on the anchorage set of wedge-type anchorages in the current specifications [30-32]. Thus, according to this calculation, it 

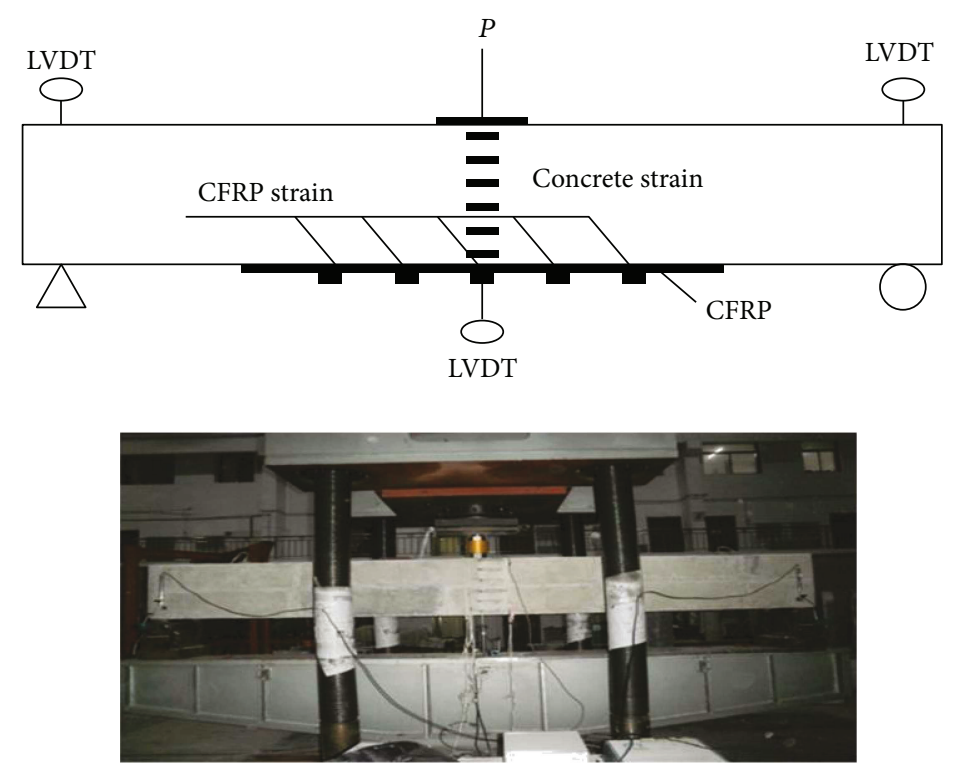

Figure 10: Test setup.

TABLE 6: Short-term prestress loss for test beams.

\begin{tabular}{lccc}
\hline Specimen & Prestress loss (Mpa) & $\Delta_{\mathrm{a}} / \mathrm{mm}$ & Prestress loss rate (\%) \\
\hline B-GR-0-T (B1) & 108.90 & 0.76 & 15.2 \\
B-LR-0-T (B2) & 102.02 & 0.71 & 14.3 \\
B-AC-0-T (B3) & 89.93 & 0.63 & 12.6 \\
UB-GR-0-T (B4) & 102.80 & 0.72 & 14.4 \\
UB-GR-300-T (B6) & 81.83 & 0.57 & 11.5 \\
UB-NG-300-T (B5) & 86.90 & 0.61 & 12.2 \\
Average value & - & 0.67 & 13.4 \\
Flat anchorage in code [31] & - & 2.00 & 1.00 \\
Waveform anchorage in code [31] & - & 4.00 & 1.00 or 1.20 \\
Xue and Zeng [29] & - & 0.8 & \\
Wang and Dai [7] & - & & \\
In this paper & &
\end{tabular}

is necessary to recommend using $0.8 \mathrm{~mm}$ as an initial anchorage set since a certain degree of safe redundancy is taken into account. As shown in Figures 11(a) and 11(b), some significant recommendations are made: (1) the CFRP strain increased linearly with the tension load at the prestressed tension stage, and the measured data of the FBG sensor embedded in the CFRP plate is highly consistent with that of the strain gauge, which is also reflected in the process of short-term prestress loss stage; (2) the prestress loss mainly occurs during the first $30 \mathrm{~min}$ after prestress force transferring to the anchorage system and the strain of the CFRP plate decreases slightly in the following testing period (about 24 hours).

5.2. Load-Midspan Deflection Responses. The load-deflection response for all the test beams is shown in Figure 12. A considerable increase of the ultimate flexural strength and bending stiffness of the strengthened beams is due to the contribution of the of posttensioned CFRP plates. In addition, the CFRP plates also improved the first-cracking and steel-yielding load compared to the unstrengthened control beam B0, indicating that the prestressed CFRP plates with the proposed anchorage system can significantly contribute to an increase of strength as well as member serviceability. The characteristics of load and respective strengthen effect for all the specimen beams are listed in Table 7 .

Figure 12(a) shows that the strengthen effect of the RC beams with initial damage and external bonded posttensioned CFRP plates (B-LS-0-T and B-CR-0-T) is superior to that of the initially strengthened beam (B-GR-0-T). The load-deflection response of the unstrengthened control beam B0, the specimen beam with external bonded posttensioned CFRP plates B-GR-0-T, the specimen beam with unbonded posttensioned CFRP plate immediately adherent to the tension surface of the RC member UB-KC-0-T, and the strengthened beam with unbonded posttensioned CFRP 


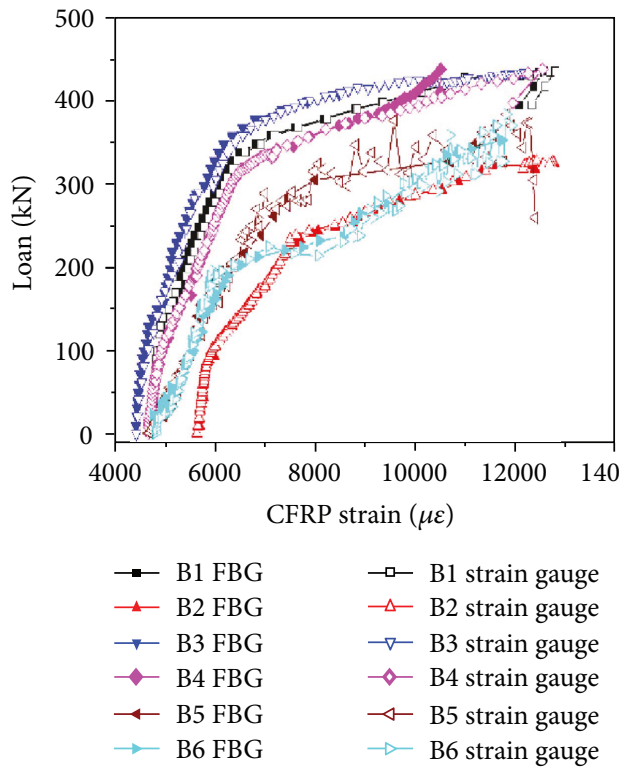

(a) Tension stage

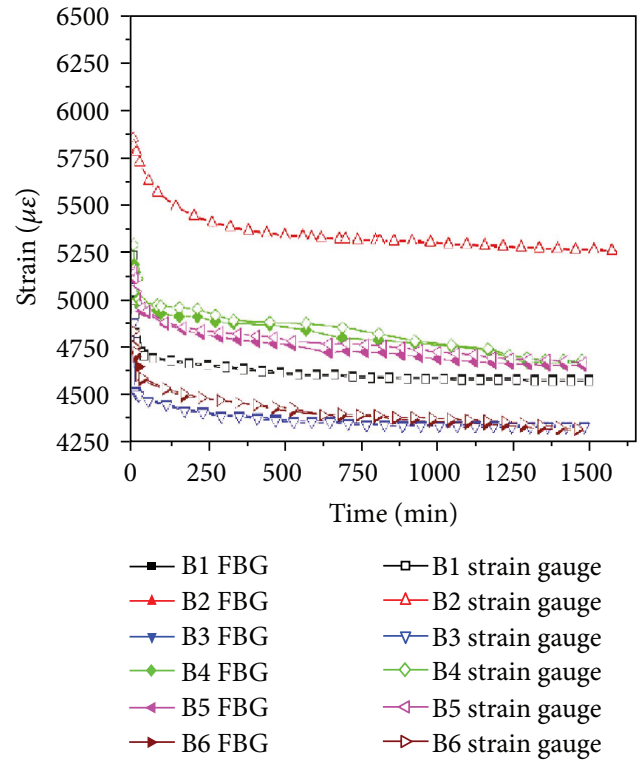

(b) Short-term prestress loss stage

FIGURE 11: Comparisons of strains between FBGs and strain gauges during the process of short-term prestress loss. Note: B1 refers to B-GR-0T; B2 refers to B-LR-0-T; B3 refers to B-AC-0-T; B4 refers to UB-GR-0-T; B5 refers to UB-GR-300-T; B6 refers to UB-NG-300-T.

plate anchored on the ungrooved tension surface of the concrete beam UB-NC-0-T are given in Figure 12(b). The ultimate flexural capacity of the beam UB-GR-0-T is approximately equal to the beam B-GR-0-T, showing that the adhesive interlayer has no effect on the ultimate flexural capacity of the strengthened RC beams. In contrast, the ultimate flexural capacity of the ungrooved beam UB-NG$0-\mathrm{T}$ is lower than that of the beam B-GR-0-T by $12 \%$, due to strain incompatibility between the CFRP plates and the neighboring concrete surface. The CFRP strain along the longitudinal direction of the whole length is identical anywhere, which is equal to the mean concrete strain at the bottom surface of RC beams.

The unbonded CFRP plate-strengthened beam was chosen to investigate the effect of the dead load before strengthening RC beams, which were preloaded to $300 \mathrm{kN}$, approximately $75 \%$ of the ultimate load-carrying capacity of the unstrengthened control beam, and were unloaded before strengthening; in other words, the CFRP was applied under conditions of no external applied load. Figure 12(c) shows that there are no obviously differences in the stiffness before the longitudinal steel yielding; the stiffness of the beams UB-GR-300-T and UB-UG-300-T is weaker than that of UB-GR-0-T and UB-UG-0-T, respectively, and stronger than that of $\mathrm{B} 0$ after the longitudinal yielding. It can be seen that the strengthening effect for first-cracking load, steelyielding load, ultimate load, and corresponding displacement of the beams UB-GR-300-T and UB-UG-300-T is inconspicuous comparing to the initially strengthened specimens UBGR-0-T and UB-UG-0-T, as shown in Table 7.

5.3. Load-CFRP Plate Strain Responses. Figure 13 represents the load-CFRP plate strain responses of the posttensioned CFRP-strengthened beams. From Figure 13(a), it can be seen that there is no apparent increase in the CFRP plate strain until the initial crack is formed due to the largest flexural stiffness as the entire cross section was a noncracked section in the precracking stage, but the strain begins to increase as the initial crack is generated because the stress redistribution occurs in the section at the maximum moment position due to the initial crack and subsequent development of the primary crack and secondary crack and the CFRP plate undertakes more load than precracking stage, which leads to a greater strain growth till the steel reinforcement yields. The strain of the CFRP plates significantly increased after the yielding of the steel bars because CFRP plates had to carry all of the loads, which induces the load-CFRP plate strain responses curves to be typically divided into two stages: preyield stage and prefailure stage, and the strain in the CFRP plate was reached to $13,000 \mu \varepsilon$ before its failure. It was also confirmed that the occurrence of the initial cracking in the concrete and the yielding of steel bar was delayed as the application of the prestressing of the CFRP plates. Figure 13(b) also shows that the uniform distribution of strain along the length of the unbonded prestressed CFRP strips at different loading levels, inferring that the CFRP strain incremental was equal to that of the beam soffit at the tension edge for the unbonded CFRP plates.

5.4. Ductility Index. Ductility under the static load refers to the measure of performance of a concrete structure that can maintain inelastic deformation before failure without any significant reduction in the ultimate strength. The most classic quantitative measure of static ductility is the displacement ductility factor, which is typically defined as the ratio of the ultimate deflection to yield deflection, $\delta_{\mathrm{pu}} / \delta_{\mathrm{py}}$ [15]. Table 7 shows the static ductility indices for all the test beams. It can be seen that the posttensioned CFRP plates 


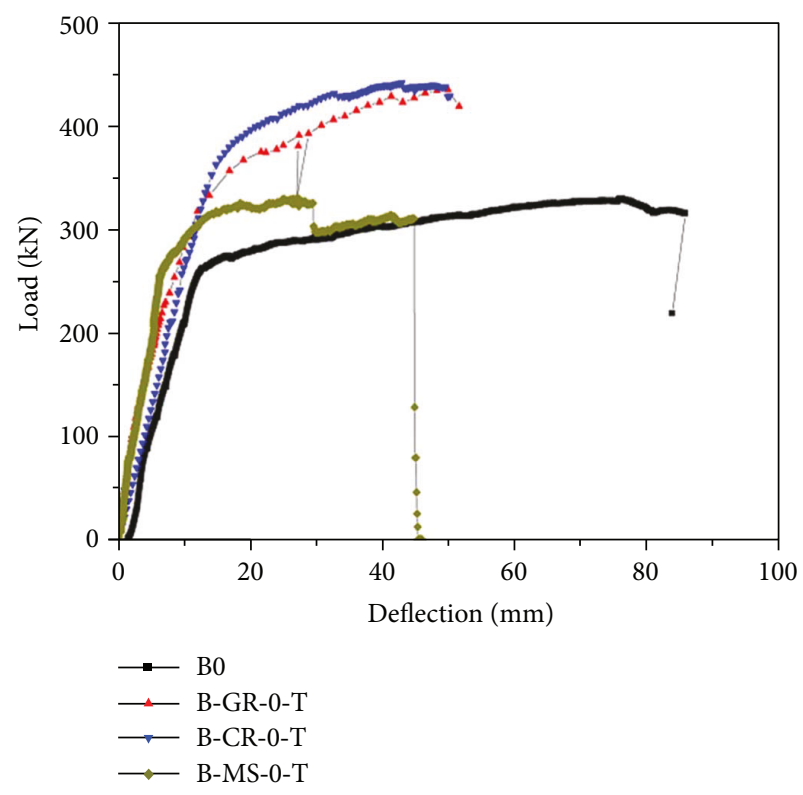

(a) Different initial damage

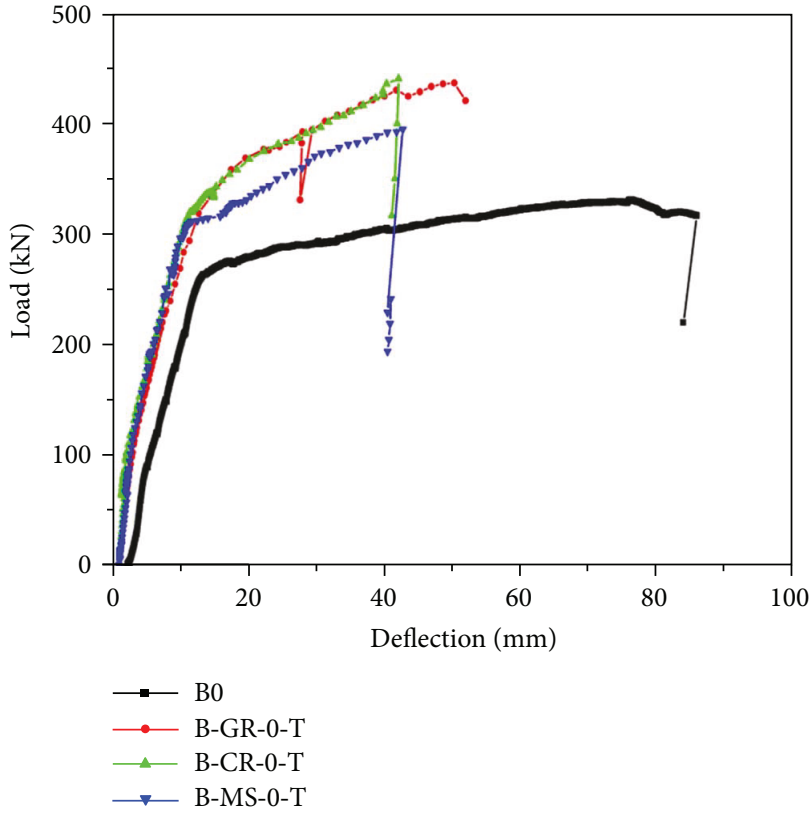

(b) Different strengthening methods

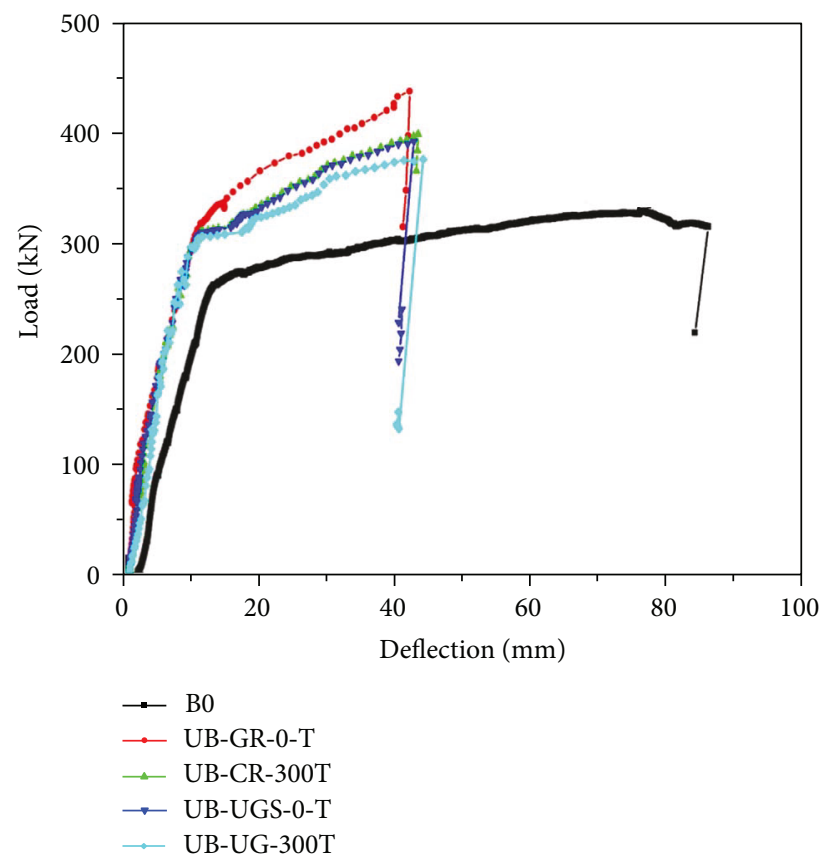

(c) Different dead load before strengthening

FIGURE 12: Load-deflection response for the strengthened RC beams.

resulted in a decrease in the ductility index compared to that of the unstrengthened beam in general. In addition, we can find that the ductility index increases as the reinforcement ratio is reduced by comparing the results of B-GR-0-T and B-MS-0-T. A significant drop of the ductility index for the beam B-CR-0-T occurred because of the lower initial stiffness caused by the artificial crack, resulting in a greater yield deflection in contrast to the beam B-GR0 -T and B-MS-0-T.

The ductility of the beam UB-GR-0-T was lower than that of B-GR-0-T by $35.98 \%$, indicating that the unbonded strengthening method may result in detrimental effect from the only viewpoint of ductility. The ductility index of the UB-GR-300-T and UB-NG-300-T with the initial damage induced by the dead load before strengthening showed a slight decrease by comparison with UB-GR-0-T and UBNG-0-T, because the steel reinforcements in tension have been yielded due to the dead load before strengthening, which lead to the generation of residual deformation after unloading. The large scale of the strengthened RC beams may result in an unobtrusive effect on the ductility index, only about $2.9 \%$. 
TABLE 7: Summary of test results.

\begin{tabular}{|c|c|c|c|c|c|c|c|c|c|c|c|c|}
\hline Specimen & $\begin{array}{l}\text { Cracking } \\
\text { load }(\mathrm{kN})\end{array}$ & $\begin{array}{c}\text { Effect } \\
(\%)\end{array}$ & $\begin{array}{l}\text { Yielding } \\
\text { load }(\mathrm{kN})\end{array}$ & $\begin{array}{l}\text { Effect } \\
(\%)\end{array}$ & $\begin{array}{l}\text { Yielding } \\
\text { deflection } \\
(\mathrm{mm})\end{array}$ & $\begin{array}{c}\text { Effect } \\
(\%)\end{array}$ & $\begin{array}{l}\text { Ultimate } \\
\text { load }(\mathrm{kN})\end{array}$ & $\begin{array}{c}\text { Effect } \\
(\%)\end{array}$ & $\begin{array}{l}\text { Ultimate } \\
\text { deflection } \\
(\mathrm{mm})\end{array}$ & $\begin{array}{c}\text { Effect } \\
(\%)\end{array}$ & $\begin{array}{c}\text { Ductility } \\
\text { index }\end{array}$ & $\begin{array}{c}\text { Failure } \\
\text { mode }\end{array}$ \\
\hline B0 & 54.5 & - & 262.3 & & 12.66 & - & 331.4 & - & 85.84 & - & 6.78 & $\mathrm{CY}$ \\
\hline B-GR-0-T & 67.4 & 23.67 & 337.5 & 28.67 & 11.19 & 9.56 & 438.5 & 32.3 & 51.66 & 66.16 & 4.62 & IC \\
\hline B-CR & 47.2 & - & 258.3 & - & 12.02 & - & 311.6 & - & 84.84 & - & 6.99 & $\mathrm{CY}$ \\
\hline B-CR-0-T & 68.5 & 45.12 & 376.8 & 45.88 & 16.88 & 40.43 & 438.7 & 40.6 & 50.48 & 68.07 & 2.99 & DR \\
\hline B-MS & 50.2 & - & 154.3 & - & 11.81 & - & 198.6 & - & 79.38 & - & 6.72 & $\mathrm{CY}$ \\
\hline B-MS-0-T & 81.0 & 61.35 & 228.5 & 48.09 & 8.30 & 47.07 & 331.9 & 67.12 & 52.81 & 50.31 & 6.36 & DR \\
\hline UB-GR-0-T & 80.2 & 47.16 & 325.5 & 19.9 & 11.71 & 8.11 & 437.7 & 32.08 & 39.77 & 115.8 & 3.39 & $\begin{array}{l}\text { CFRP } \\
\text { rupture }\end{array}$ \\
\hline UB-GR-300-T & 74.8 & 37.25 & 314.5 & 24.1 & 12.26 & 3.26 & 395.5 & 19.34 & 40.36 & 112.7 & 3.29 & $\begin{array}{l}\text { CFRP } \\
\text { rupture }\end{array}$ \\
\hline UB-NG-0-T & 77.4 & 42.02 & 312.3 & 19.06 & 11.76 & 7.65 & 392.8 & 18.53 & 40.47 & 112.1 & 3.44 & $\begin{array}{l}\text { CFRP } \\
\text { rupture }\end{array}$ \\
\hline UB-NG-300-T & 73.7 & 35.22 & 330 & 25.81 & 12.09 & 4.71 & 377.6 & 13.94 & 40.92 & 109.7 & 3.38 & $\begin{array}{l}\text { CFRP } \\
\text { rupture }\end{array}$ \\
\hline
\end{tabular}

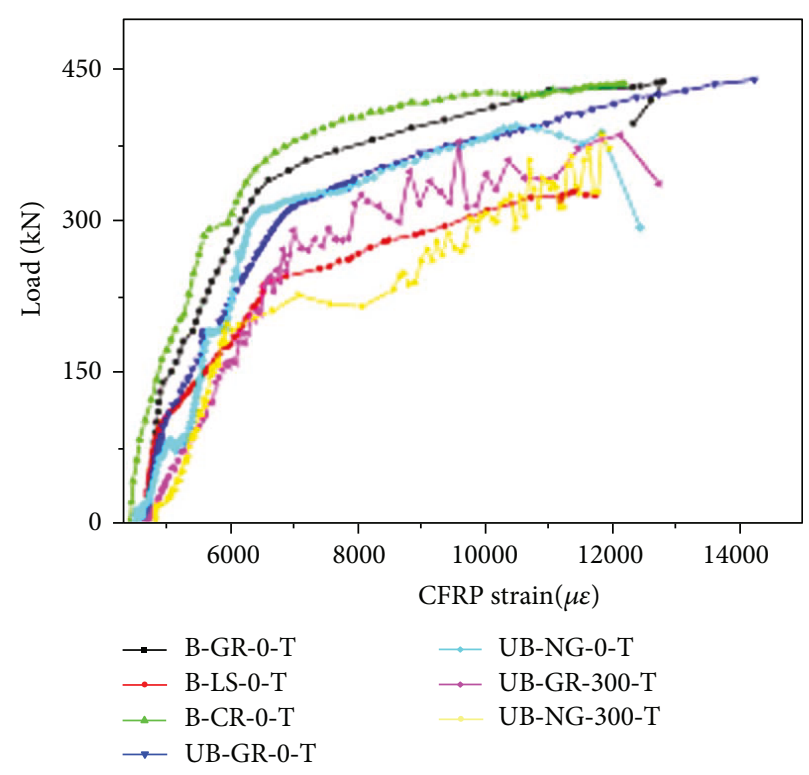

(a) The whole loading stage

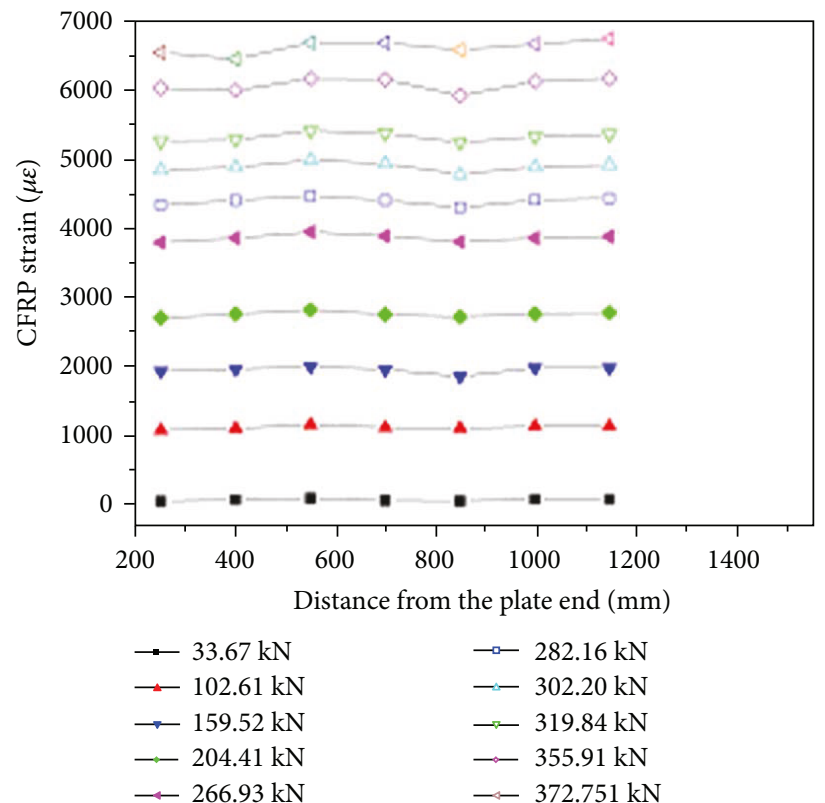

(b) The strain distribution of the unbonded CFRP plate

FIGURE 13: CFRP plates strain measurements.

5.5. Failure Modes and Crack Pattern. The three unstrengthened beams (B0, B-CR, and B-MS) failed in a conventional flexural failure pattern with the concrete crushed in compression zone and longitudinal tensile reinforcements yielding in tension zone at the midspan of the beam. The cracking load, yielding load, and ultimate load of the Beam B-CR and B-MS were less than that of $\mathrm{B} 0$ due to initial damage. A typical pattern of crack formation and evolution was observed, as shown in Figure 14(a). For all the strengthened RC beams with bonded posttensioned CFRP plates, IC debonding occurs at the maximum moment position up to the anchorage as shown in Figure 14(b).
The bonded CFRP-plated beams performed similarly as the unbonded CFRP-plated beams and the CFRP plates ruptured in a similar way under the ultimate load, as shown in Figure 14(a). The failure of the B-GR-0-T starts as concrete crush in compression zone accompanied with the adhesive interlayer cracking and the IC debonding, as shown in Figure 14(b). The first flexural crack occurred in the midspan of the strengthened beam when it was loaded at $67.4 \mathrm{kN}$ and spread to the compression zone of the concrete gradually. The stiffness of the beam B-GR-0-T decreased significantly and flexural cracks continued to propagate rapidly after the yielding of the longitudinal reinforcements, when the load 


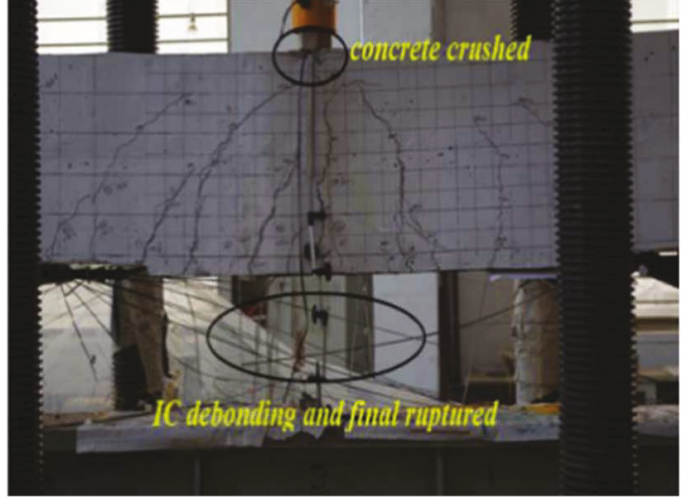

(a) DR failure

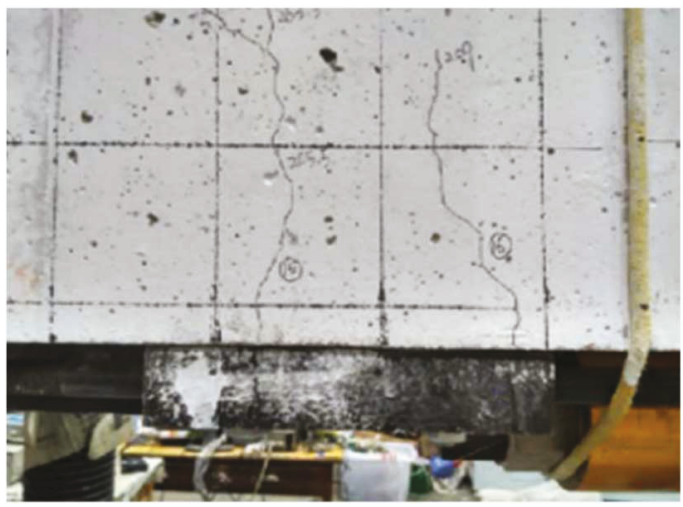

(c) Vertical crack in the anchorage

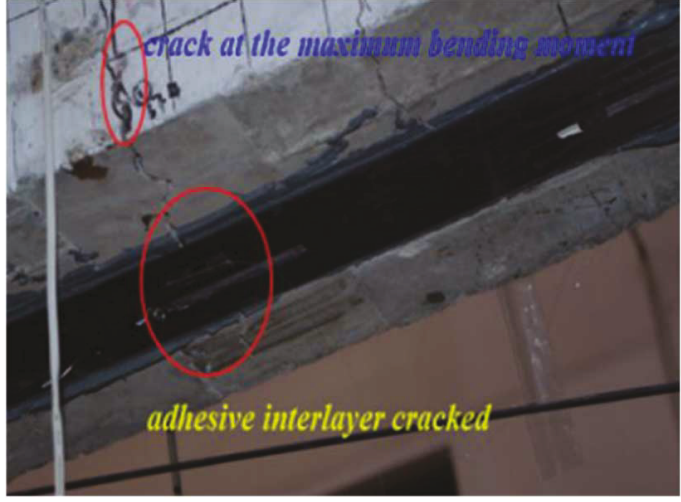

(b) IC debonding and CFRP splitting

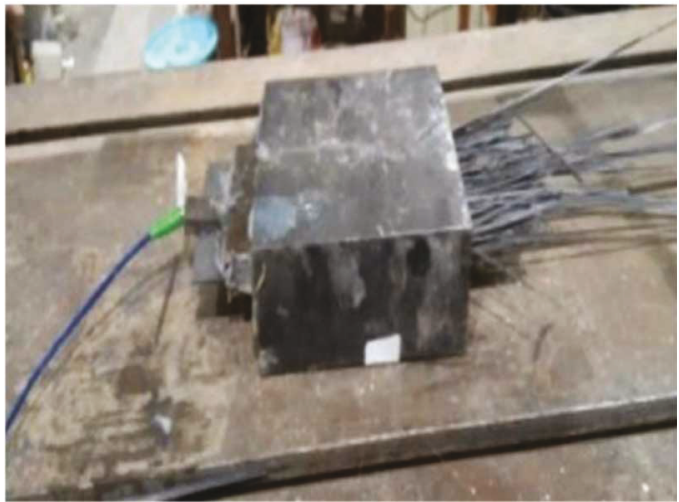

(d) CFRP fracture at the anchorage

FIgURE 14: Typical failure modes for the strengthened RC beams.

was increased to $337 \mathrm{kN}$. The CFRP plate splits off locally at a load of $415 \mathrm{kN}$. After the ultimate flexural bearing capacity was reached at a load of $438 \mathrm{kN}$, crush of the concrete occurred in the compressive zone, followed by a sudden drop of the flexural capacity of RC member, indicating that the beam B-GR-0-T completely failed.

As seen in Figure 14(c), the remaining strengthened RC beams with bonding CFRP plates exhibited similar failure mode, which originated from an intermediate flexural crack at the maximum bending moment, followed by the IC debonding and the progressive rupture of the CFRP plate and eventually the crush of the concrete in the compressive zone. With regard to the beams UB-GR-300-T and UBNG-300-T, which were preloaded with $300 \mathrm{kN}$, it is remarkable that the tensile steel rebars of beam had yielded. At the time of strengthening, numerous flexural cracks formed in the vicinity of the maximum bending moment. Under the prestressing of the CFRP plates, the antiarch of the strengthened RC beam occurred, so that the concrete flexural cracks in the tension zone are substantially closed, and by contrast, a few reverse flexural cracks occurred at the compression zone. The cracks that had been closed at the time of strengthening were continuously propagated upward once again, and a number of additional cracks between these exiting cracks were formed as the additional load increased subsequently.

The tensile failure of the CFRP plates indicates that the excellent mechanical performance of the CFRP plates in tension is fully exploited due to overcoming the premature strip debonding from the end anchorage system in spite of a small amount of vertical cracks appeared at the anchorage zone on the bottom side, as shown in Figure 14(c). The CFRP plates were fully damaged into wires at the intersecting parts of the CFRP plates and wedge clips, as shown in Figure 14(d). It can clearly be seen that there is no visible indication of any slippage between the CFRP plate and the wedge clip, and no damage occurred in any of the test specimens caused by contact pressure applied to the CFRP plate by the wedge clips.

\section{Conclusion}

In this paper, a self-sensing FBG-CFRP composite plate is developed. An experimental study in investigating the short-term prestressing losses and flexural behavior of RC beams strengthened with posttensioned smart CFRP plates is presented. The following conclusions can be drawn:

(1) The built-in FBG sensor works well with the CFRP host matrix and effectively senses its axial strain variations with a sensing coefficient of $1.228 \mathrm{pm} / \mu \varepsilon$. The CFRP plate with built-in FBG sensor can monitor the axial strain at stress hot spot with high accuracies under each loading step in the prestressing application stage and short-term prestress loss stage. 
(2) The prestress losses of CFRP plates obtained by the FBG-CFRP plate in the posttensioned system presented in this study are dominated by the shortterm anchorage deformation and the retracted value of CFRPs, approximately $11.5 \%$ to $15.2 \%$ of the initial prestress. The anchorage set of the wedge-type anchorage was ranged from $0.57 \mathrm{~mm}$ to $0.76 \mathrm{~mm}$ for the specimen beams listing in Table 3 with the average value of $0.67 \mathrm{~mm}$, which is relatively smaller than that of the flat anchorage and waveform anchorage provided by the current specifications.

(3) For all the strengthened RC beams, prestressed CFRP plates not only can significantly improve serviceability of reinforced concrete beams by increasing member stiffness because of increase and delay of first-cracking and steel-yielding load, but also enhance the flexural loading capacity of reinforced concrete beams compared to an unstrengthened concrete beam.

(4) The strengthening effect of the first-cracking load, steel-yielding load, and the ultimate load for external bonded posttensioned CFRP plate-strengthened RC beams with initial damage is superior to that of the strengthened nondestructive beam. It is obviously that the first-cracking load, steel-yielding load, and the ultimate load of the specimen B-GR-0-T are $23.67 \%, 28.67 \%$, and $32.3 \%$ higher than that of the unstrengthened control beam. By contrast, the critical load mentioned above of the specimen B-CR-0$\mathrm{T}$ and $\mathrm{B}-\mathrm{MS}-0-\mathrm{T}$ is enhanced $45.12 \%, 45.88 \%$, and $40.6 \%$ and $61.35 \%, 48.09 \%$, and $67.12 \%$ by comparing to the unstrengthened control beam, respectively. In addition, we can find that the strengthening effect of the critical load and the ductility index increases as the steel reinforcement ratio is reduced by comparing the results of B-GR-0-T and B-MS-0-T. It can be seen that a significant drop of the ductility index for the specimen beam B-CR-0-T occurred because of that the lower initial stiffness caused by the artificial crack results in a greater yield deflection in contrast to the specimens B-GR-0-T and B-MS-0-T.

(5) There are no obvious differences in the stiffness before the longitudinal steel yielding; the stiffness of beams UB-GR-300-T and UB-UG-300-T is weaker than that of UB-GR-0-T and UB-UG-0-T, respectively, and stronger than that of $\mathrm{B} 0$ after the longitudinal yielding, the strengthening effect for first-cracking load, steel-yielding load, ultimate load, and corresponding displacement of the specimen beams UB-GR300-T and UB-UG-300-T are inconspicuous comparing to the initially strengthened specimens UB-GR-0-T and UB-UG-0-T. The ductility index of the specimen UB-GR-300-T and UB-NG-300-T with the initial damage induced by the dead load before strengthening showed a slight decrease by comparison with UB-GR-0-T and UB-NG-0-T, because the steel reinforcements in tension have been yielded due to the dead load before strengthening, which lead to the generation of residual deformation after unloading.

\section{Additional Points}

Zhou Zhi is a professor of Dalian University of Technology. He received his Ph.D. degree from the Department of Engineering Mechanics of Harbin Institute of Technology, in 2003. Since 1999, he has been engaged in optical fiber sensing, structure health monitoring, and other fields. $\mathrm{He}$ published more than 80 academic articles and more than 50 included by SCI and EI, National Invention Patent 15.

\section{Conflicts of Interest}

The authors declare there are no conflicts of interest regarding the publication of this paper.

\section{Acknowledgments}

This research was supported by "Research and development of F-P distributed large strain sensors o coaxial cable (61675038)" sponsored by Chinese National Natural Science Foundation.

\section{References}

[1] L. C. Hollaway, J. G. Teng, and L. Lam, Strengthening and Rehabilitation of Civil Infrastructures Using Fiber-Reinforced Polymer (FRP) Composites, Woodhead Publishing Limited, Boca Raton, USA, 2008.

[2] M. Motavalli, C. Czaderski, and K. Pfyl-Lang, "Prestressed CFRP for strengthening of reinforced concrete structures: recent developments at Empa, Switzerland," Journal of Composites for Construction, vol. 15, no. 2, pp. 194-205, 2011.

[3] M. N. Fardis and H. H. Khalili, "Concrete encased in fiberglass-reinforced plastic," ACI Journal Proceedings, vol. 78, no. 6, pp. 440-446, 1981.

[4] M. N. Fardis and H. H. Khalili, "FRP-encased concrete as a structural material," Magazine of Concrete Research, vol. 34, no. 121, pp. 191-202, 1982.

[5] A. L. Marshall, "Commentary (with reply) on article: FRPencased concrete as a structural material, by Fardis, M. N., and Khalili, H.H," Magazine of Concrete Research, vol. 35, no. 12, pp. 242-243, 1983.

[6] J. Diab and J. P. Cook, The Strength of Concrete Beams Reinforced with Plates of Fiber Reinforced Plastic, Presented at Spring Meeting of American Society of Civil Engineers, Atlanta, GA, 1984.

[7] M. Deuring, "Strengthening of reinforced concrete using prestressed FRP,” 1993, Diss. ETH No. 10199, EMPA Bericht Nr. 224, Empa Dübendorf, 279 (in German).

[8] R. J. Quantrill and L. C. Hollaway, "The flexural rehabilitation of reinforced concrete beams by the use of prestressed advanced composite plates," Composites Science and Technology, vol. 58, no. 8, pp. 1259-1275, 1998.

[9] R. G. Wight and M. F. Green, "Prestressed FRP sheets for poststrengthening reinforced concrete beams," Journal of Composites for Construction, vol. 5, no. 4, pp. 214-220, 2001. 
[10] R. El-Hacha, R. G. Wight, and M. F. Green, "Prestressed carbon fiber reinforced polymer sheets for strengthening concrete beams at room and low temperatures," Journal of Composites for Construction, vol. 8, no. 1, pp. 3-13, 2004.

[11] M. Aram, C. Czaderski, and M. Motavalli, "Effects of gradually anchored prestressed CFRP strips bonded on prestressed concrete beams," Journal of Composites for Construction, vol. 12, no. 1, pp. 25-34, 2008.

[12] Y. C. You, K. S. Choi, and J. H. Kim, “An experimental investigation on flexural behavior of RC beams strengthened with prestressed CFRP strips using a durable anchorage system," Composites Part B: Engineering, vol. 43, no. 8, pp. 30263036, 2012.

[13] W. W. Wang and J. G. Dai, "Prestress losses and flexural behavior of reinforced concrete beams strengthened with posttensioned CFRP sheets," Journal of Composites for Construction, vol. 16, no. 2, pp. 207-216, 2012.

[14] S. S. Abdulhameed, E. Wu, and B. Ji, "Mechanical prestressing system for strengthening reinforced concrete members with prestressed carbon-fiber-reinforced polymer sheets," Journal of Performance of Constructed Facilities, vol. 29, no. 3, article 04014081, 2015.

[15] J. Michels, M. Staśkiewicz, C. Czaderski, R. Kotynia, Y. E. Harmanci, and M. Motavalli, "Prestressed CFRP strips for concrete bridge girder retrofitting: application and static loading test," Journal of Bridge Engineering, vol. 21, no. 5, article 04016003, 2016.

[16] M. Rezazadeh, "Analytical approach for the flexural analysis of RC beams strengthened with prestressed CFRP," Composites Part B: Engineering, vol. 73, pp. 16-34, 2015.

[17] L. Correia, T. Teixeira, J. Michels, J. A. P. P. Almeida, and J. Sena-Cruz, "Flexural behaviour of RC slabs strengthened with prestressed CFRP strips using different anchorage systems," Composites Part B Engineering, vol. 81, pp. 158-170, 2015.

[18] M. R. Mostakhdemin Hosseini, "Flexural strengthening of reinforced low strength concrete slabs using prestressed NSM CFRP laminates," Composites Part B Engineering, vol. 90, pp. 14-29, 2016.

[19] L. Correia, J. Sena-Cruz, J. Michels, P. França, E. Pereira, and G. Escusa, "Durability of RC slabs strengthened with prestressed CFRP laminate strips under different environmental and loading conditions," Composites Part B Engineering, vol. 125, pp. 71-88, 2017.

[20] P. Gao, X. Gu, and A. S. Mosallam, "Flexural behavior of preloaded reinforced concrete beams strengthened by prestressed CFRP laminates," Composite Structures, vol. 157, pp. 33-50, 2016.

[21] M. Mahal, B. Täljsten, and T. Blanksvärd, "Experimental performance of RC beams strengthened with FRP materials under monotonic and fatigue loads," Construction and Building Materials, vol. 122, pp. 126-139, 2016.

[22] J. Michels and J. Sena-Cruz, "Structural strengthening with prestressed CFRP strips with gradient anchorage," Journal of Composites for Construction, vol. 17, no. 5, pp. 651-661, 2013.

[23] M. Aslam, P. Shafigh, M. Z. Jumaat, and S. N. R. Shah, "Strengthening of RC beams using prestressed fiber reinforced polymers-a review," Construction and Building Materials, vol. 82, pp. 235-256, 2015.

[24] H. Huang and W.-W. Wang, "Fatigue behavior of reinforced concrete beams strengthened with externally bonded prestressed CFRP sheets," Journal of Composites for Construction, vol. 21, no. 3, article 04016108, 2017.

[25] R. El-Hacha and M. Gaafar, "Flexural strengthening of reinforced concrete beams using prestressed, near-surface mounted CFRP bars," PCI Journal, vol. 56, no. 4, pp. 134-151, 2011.

[26] H. Nordin, Strengthening Structures with Externally Prestressed Tendons: Literature Review, Technical Report 2005: 06, Lulea University of Technology (6.3. 3 Grout-Potted Anchorages, Lulea, Sweden.

[27] R. El-Hacha and M. A. Gaafar, "Strengthening reinforced concrete beams with prestressed near surface mounted FRP strips," in Fourth international conference on FRP composites in civil engineering (CICE2008), Zurich, Switzerland, 2008.

[28] H. N. Li, D. S. Li, and G. B. Song, "Recent applications of fiber optic sensors to health monitoring in civil engineering," Engineering Structures, vol. 26, no. 11, pp. 1647-1657, 2004.

[29] K. T. Lau, C. C. Chan, L. M. Zhou, and W. Jin, "Strain monitoring in composite-strengthened concrete structures using optical fibre sensors," Composites Part B: Engineering, vol. 32, no. 1, pp. 33-45, 2001.

[30] S. W. Lu and H. Q. Xie, "Real-time simulation and evaluation of load effects for smart CFRP-strengthened RC beams," Acta Materiae Compositae Sinica, vol. 23, no. 3, pp. 158-164, 2006.

[31] S. W. Lu and H. Q. Xie, "Research of online monitoring technique for CFRP-strengthened RC beams with embedded fiber Bragg grating sensors," Journal of Basic Science and Engineering, vol. 15, no. 3, pp. 387-394, 2007.

[32] M. Amano, Y. Okabe, N. Takeda, and T. Ozaki, "Structural health monitoring of an advanced grid structure with embedded fiber Bragg grating sensors," Structural Health Monitoring, vol. 6, no. 4, pp. 309-324, 2016.

[33] Y. L. Wang and Z. Zhou, "Research on fabrication technique and sensing properties of smart FRP-FBG composite laminates," Journal of Optoelectronics: Laser, vol. 18, no. 8, pp. 900-902, 2007.

[34] B. Wang, J. G. Teng, L. De Lorenzis et al., "Strain monitoring of RC members strengthened with smart NSM FRP bars," Construction and Building Materials, vol. 23, no. 4, pp. 16981711, 2009.

[35] G. Jiang, M. Dawood, K. Peters, and S. Rizkalla, "Global and local fiber optic sensors for health monitoring of civil engineering infrastructure retrofit with FRP materials," Structural Health Monitoring, vol. 9, no. 4, pp. 309-322, 2009.

[36] Y. Wang, Y. Li, J. Ran, and M. Cao, "Experimental investigation of a self-sensing hybrid GFRP-concrete bridge superstructure with embedded FBG sensors," International Journal of Distributed Sensor Networks, vol. 2012, Article ID 902613, 10 pages, 2012.

[37] B. A. Sundaram, K. Kesavan, S. Parivallal, A. K. F. Ahmed, and K. Ravisankar, "Monitoring of FRP strengthened concrete structures using FBG sensors," Procedia Engineering, vol. 14, pp. 1549-1556, 2011.

[38] K. Kesavan, K. Ravisankar, R. Senthil, and A. K. Farvaze Ahmed, "Experimental studies on performance of reinforced concrete beam strengthened with CFRP under cyclic loading using FBG array," Measurement, vol. 46, no. 10, pp. 38553862, 2013.

[39] F. Valvona and J. Toti, "Effective seismic strengthening and monitoring of a masonry vault by using glass fiber reinforced cementitious matrix with embedded fiber Bragg grating 
sensors," Composites Part B Engineering, vol. 113, pp. 355-370, 2017.

[40] S. Zhang and T. Yu, "Fibre-reinforced polymer strengthening and fibre Bragg grating-based monitoring of reinforced concrete cantilever slabs with insufficient anchorage length of steel bars," Advances in Structural Engineering, vol. 20, no. 11, pp. 1684-1698, 2017.

[41] S. L. Burtscher, "Wedge anchorage for CFRP strips," Journal of Composites for Construction, vol. 12, no. 4, pp. 446-453, 2008.

[42] S. L. Burtscher, "Anchoring for pre-tensioned and/or stressed tensile elements," 2007, United States Patent Application, Patent No. US 2007/0221894 A1.

[43] K. O. Hill and G. Meltz, "Fiber Bragg grating technology fundamentals and overview," Journal of Lightwave Technology, vol. 15, no. 8, pp. 1263-1276, 1997.

[44] Z. Zhou, M. Huang, L. Huang, J. Ou, and G. Chen, "An optical fiber Bragg grating sensing system for scour monitoring," Advances in Structural Engineering, vol. 14, no. 1, pp. 67-78, 2011.

[45] M. Huang, Z. Zhou, S. Yue, J. He, and J. Ou, "A novel durable intelligent fiber reinforced polymer anchor with embedded optical fiber Bragg grating sensors," Science China Technological Sciences, vol. 55, no. 5, pp. 1455-1462, 2012. 


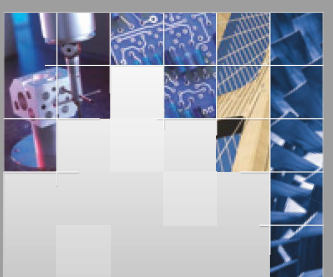

\section{Enfincering}
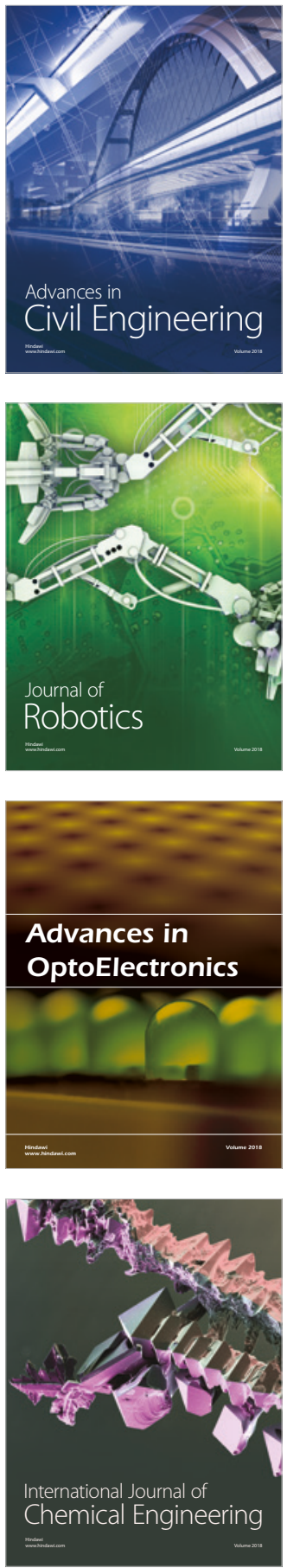

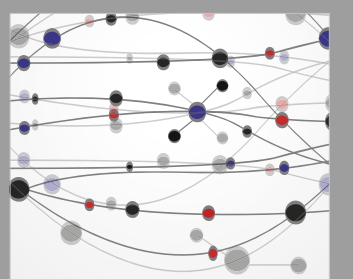

\section{Rotating \\ Machinery}

The Scientific World Journal

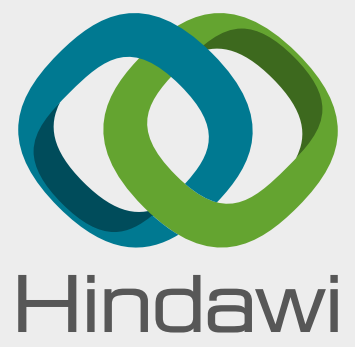

Submit your manuscripts at

www.hindawi.com
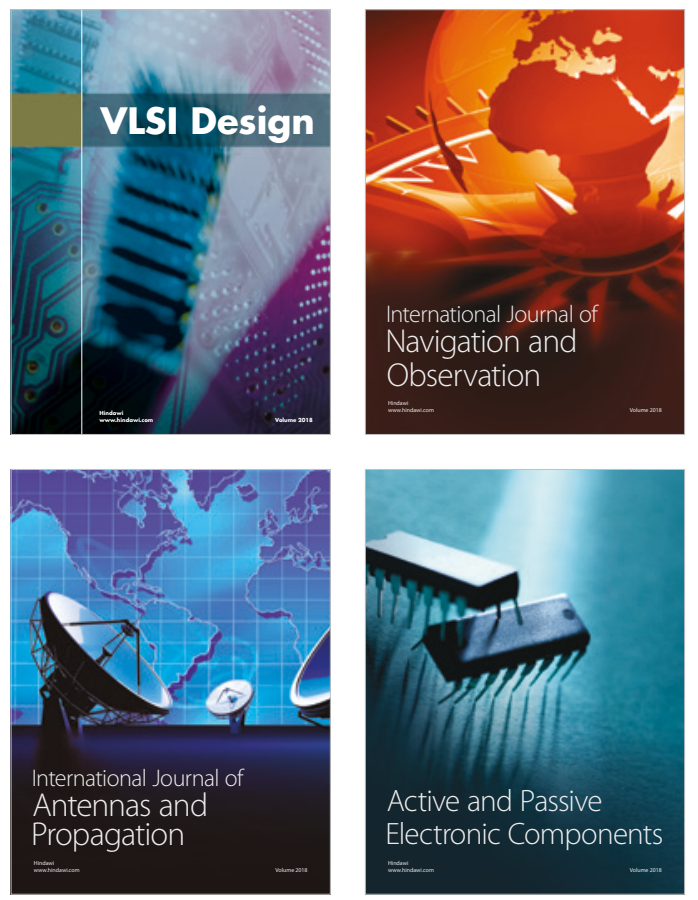
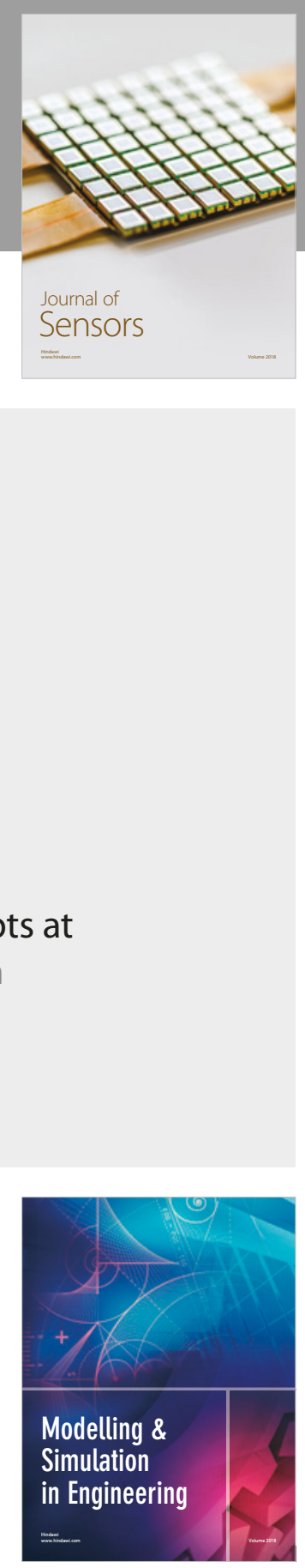

\section{Advances \\ Multimedia}
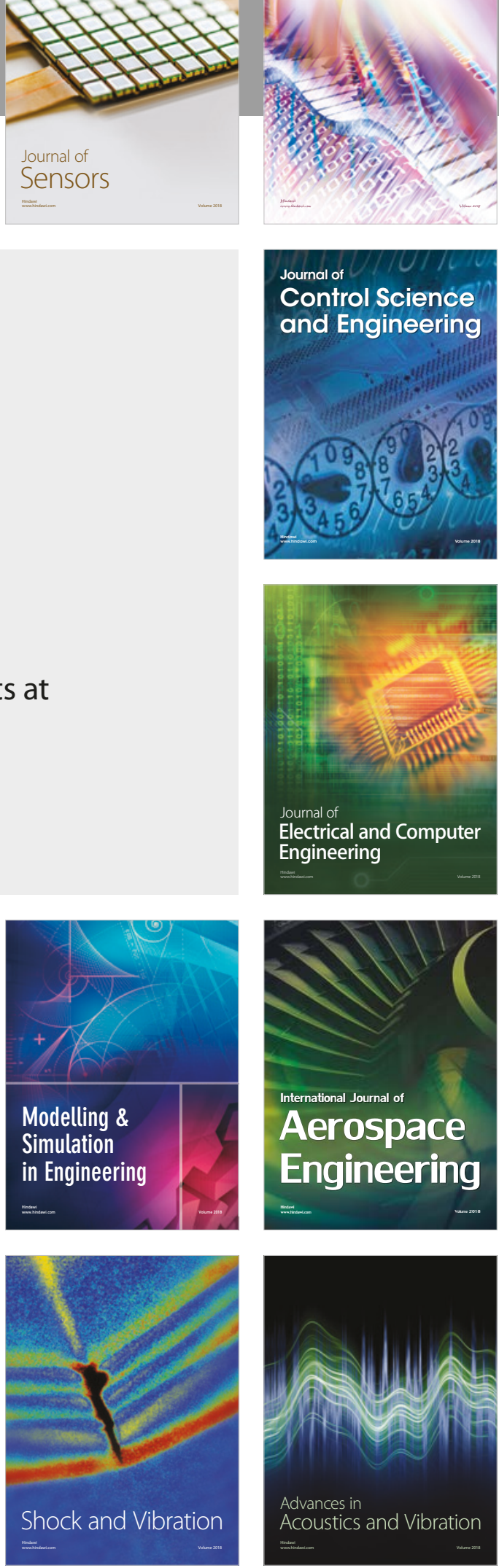